\title{
Glutathione/pH-responsive nanosponges enhance strigolactone delivery to prostate cancer cells
}

\author{
Monica Argenziano ${ }^{1}$, Chiara Lombardi ${ }^{2}$, Benedetta Ferrara ${ }^{1}$, Francesco Trotta ${ }^{2}$, \\ Fabrizio Caldera², Marco Blangetti ${ }^{2}$, Hinanit Koltai ${ }^{3}$, Yoram Kapulnik ${ }^{3}$, Ronit \\ Yarden ${ }^{4}$, Luca Gigliotti ${ }^{5}$, Umberto Dianzani ${ }^{5}$, Chiara Dianzani ${ }^{1}$, Cristina Prandi ${ }^{2}$ \\ and Roberta Cavalli ${ }^{1}$ \\ ${ }^{1}$ Department of Drug Science and Technology, University of Turin, Turin, Italy \\ ${ }^{2}$ Department of Chemistry, University of Turin, Turin, Italy \\ ${ }^{3}$ Agricultural Research Organization, Volcani Center, Rishon LeTsiyon, Israel \\ ${ }^{4}$ Georgetown University Medical Center, Washington DC, USA \\ ${ }^{5}$ Department of Health Sciences, Universita del Piemonte Orientale, Novara, Italy \\ Correspondence to: Roberta Cavalli, email: roberta.cavalli@unito.it \\ Keywords: strigolactones; GSH/pH-responsive nanosponges; prostate cancer cells; controlled release; intracellular delivery \\ Received: December 28, $2017 \quad$ Accepted: October 24, $2018 \quad$ Published: November 09, 2018 \\ Copyright: Argenziano et al. This is an open-access article distributed under the terms of the Creative Commons Attribution License 3.0 (CC \\ BY 3.0), which permits unrestricted use, distribution, and reproduction in any medium, provided the original author and source are credited.
}

\section{ABSTRACT}

Strigolactones (SLs) are carotenoid-derived plant hormones that exhibit anticancer activities. We previously demonstrated that two SL analogues, MEB55 and ST362, inhibit the growth and survival of various cancer cell lines. However, these compounds have low aqueous solubility and stability at physiological pH. Here, we generated SL-loaded glutathione/pH-responsive nanosponges (GSH/pH-NS) to selectively deliver SLs to prostate cancer cells and enhance their therapeutic efficacy. The SLs were readily incorporated into the GSH/pH-NS. The drug loading efficiency was $13.9 \%$ for MEB55 and $\mathbf{1 5 . 4 \%}$ for ST362, and the encapsulation efficiency was $88.7 \%$ and $96.5 \%$, respectively. Kinetic analysis revealed that release of MEB55 and ST362 from the GSH/pH-NS was accelerated at acidic pH and in the presence of a high GSH concentration. Evaluation of the effects of MEB55- and ST362-loaded GSH/pH-NS on the growth of DU145 (high GSH) and PC-3 (low GSH) prostate cancer cells revealed that the GSH/pH-NS inhibited the proliferation of DU145 cells to a greater extent than free MEB55 or ST362 over a range of concentrations. These findings indicate GSH/ pH-NS are efficient tools for controlled delivery of SLs to prostate cancer cells and may enhance the therapeutic efficacy of these compounds.

\section{INTRODUCTION}

Natural compounds with therapeutic activity can be exploited for cancer treatment because they are biocompatible and have well-characterized functions. Various plant-derived bioactive compounds have been shown to inhibit cancer cell growth and survival. Strigolactones (SLs) are carotenoid-derived plant hormones that are synthesized by plant roots and released into the rhizosphere [1-5]. SLs have a four-ring structure consisting of a tricyclic lactone (ABC rings) linked to a methyl butenolide (D ring) through an enol ether bridge (Figure 1). They are indispensable for the establishment of arbuscular mycorrhizae [6-9]. We previously demonstrated that two SL analogues, MEB55 and ST362 (Figure 1), could induce $\mathrm{G} 2 / \mathrm{M}$ cell cycle arrest and apoptosis in a variety of human cancer cell lines in vitro. Additionally, they inhibited the growth of breast cancer stem cell-enriched mammospheres and human breast cancer xenograft tumors in vivo [10-11].

MEB55 was previously shown to have high antitumor efficacy and relatively low toxicity compared to conventional chemotherapeutics. Specifically, MEB55 disrupted the integrity of microtubule networks and inhibited the migration of highly invasive breast cancer cell lines [12]. More recently, SLs were found to promote 
genomic instability and cell death by inducing DNA damage and inhibiting DNA repair [13]. Although SL analogues are stable and readily available, they have several limitations including low aqueous solubility at basic $\mathrm{pH}$ [14]. The butenolide D-ring, which is the bioactiphore portion of the molecule, is easily hydrolyzed to generate an inactive compound. Therefore, more soluble and stable formulations are required for clinical applications.

Nanocarriers facilitate selective drug delivery and sustained release at target sites, thereby enhancing drug efficacy and reducing toxicity. The incorporation of drugs into nanocarriers can enhance their aqueous solubility and stability, because they protect them from the external environment. Nanocarriers can also alter the pharmacokinetics and biodistribution of the encapsulated drugs, and promote accumulation in tumor tissue owing to the enhanced permeation and retention (EPR) effect and cell internalization capability [15]. Nanocarrier-based drug delivery systems have therefore been developed to deliver therapeutics to tumors and enhance their effects [16-19]. For example, $\beta$-cyclodextrin $(\beta-C D)$ - based nanosponges (NS) are solid, hypercrosslinked polymers with spherical morphologies that are a versatile platform for drug delivery [20-26].

Stimuli-responsive nanocarriers can allow sustained release of the encapsulated drugs in response to conditions in the microenvironment such as $\mathrm{pH}$, enzyme concentrations, or redox gradients associated with various pathological states including neoplastic disease [27]. For example, glutathione (GSH)/pH-responsive NS (GSH/ $\mathrm{pH}-\mathrm{NS}$ ) allow the controlled release of various drugs in response to the intracellular GSH concentration and $\mathrm{pH}$ [28-31]. The concentration of GSH is higher in tumor compared to normal tissue $(0.5-10 \mathrm{mM}$ vs. $2-20 \mu \mathrm{M})$ [32]. Additionally, the $\mathrm{pH}$ in the tumor microenvironment is more acidic than in normal tissue and blood ( $\mathrm{pH} 6.2-6.9$ vs. $\mathrm{pH}$ 7.4). NS are $\mathrm{pH}$ - and GSH-responsive owing to the presence of disulfide bridges and carboxyl groups in the GSH/ pH-NS polymer matrix. Thus, a high intracellular GSH concentration can promote drug release from nanoparticles containing redox-sensitive chemical groups [28, 33-34].

$\mathrm{GSH} / \mathrm{pH}-\mathrm{NS}$ have been designed to deliver anticancer drugs to cells with high GSH levels. Importantly, doxorubicin-loaded GSH-targeted NS exhibited greater efficacy against cancer cells with high GSH content compared to free doxorubicin [35]. We hypothesized that GSH/pH-NS could enable the targeted delivery and controlled release of SL analogues (MEB55 and ST362) in prostate cancer cells thereby enhancing the therapeutic efficacy.

\section{RESULTS}

We generated GSH/pH-NS in order to deliver two SL analogues (ST362 and MEB55) to prostate cancer
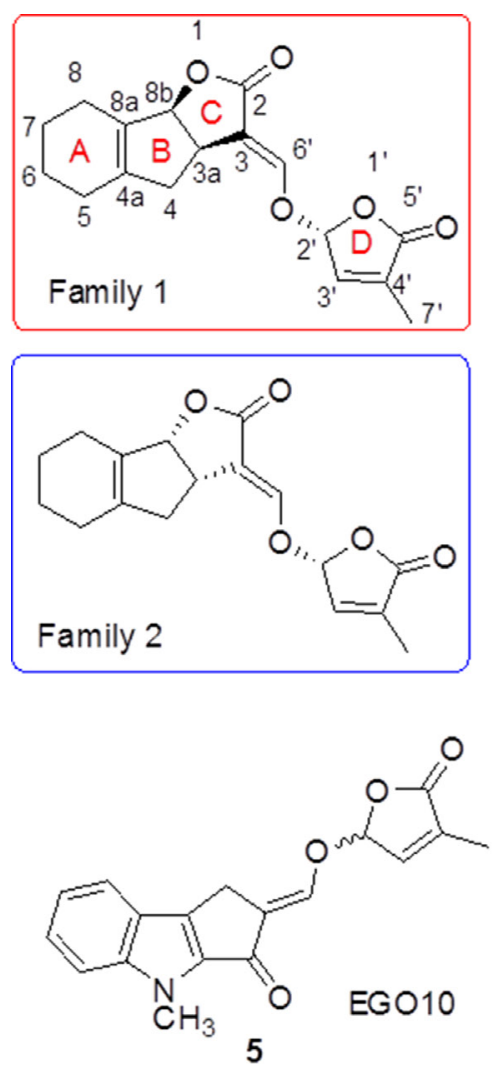
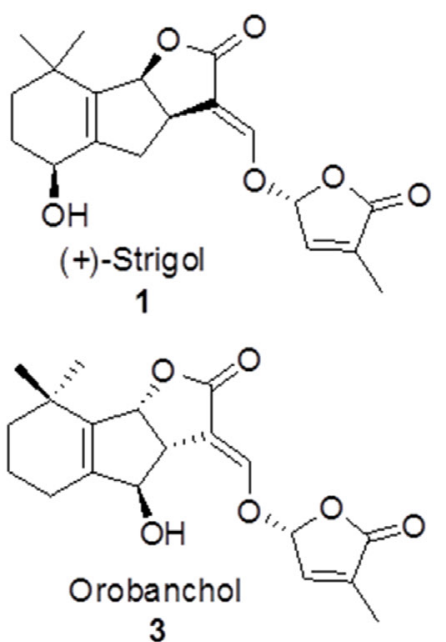

3

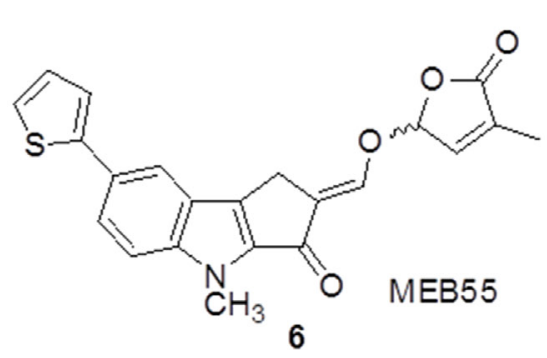

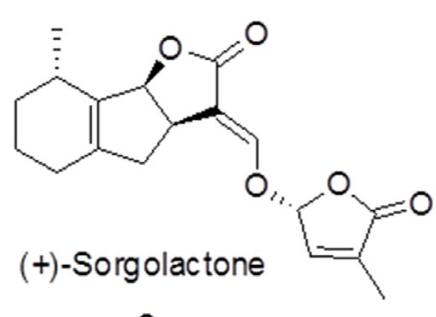

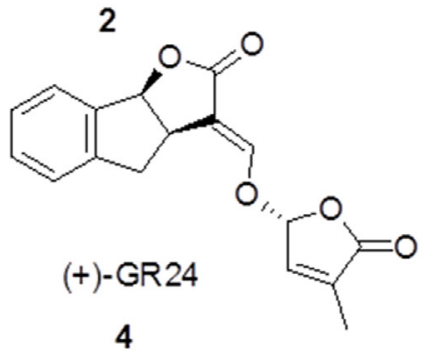

4

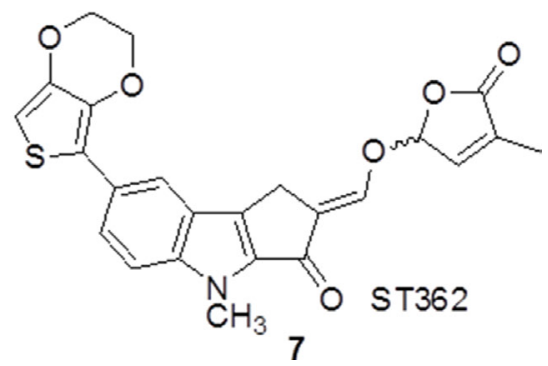

Figure 1: Chemical structures of several natural (Strigol, Sorgolactone, and Orobanchol) and synthetic SLs (GR24, EGO10, MEB55, and ST362). 
cells. We first performed elemental analysis and solid-state nuclear magnetic resonance (SSNMR) spectroscopy to characterize unloaded (blank) GSH/pH-NS. The elemental analysis confirmed the presence of disulfide groups in the nanostructures. Additionally, CHNS analysis demonstrated carbon and hydrogen contents of $49.42 \%$ and $4.56 \%$, respectively. The sulfur content was $0.74 \%$, which was consistent with a previous report [28]. However, it was lower than the expected value of $0.97 \%$, suggesting that 2-hydroxyethyl disulfide has less reactivity as crosslinking agent than pyromellitic dianhydride. The ${ }^{13} \mathrm{C}$ cross-polarization/magic angle spinning (13C CP/MAS) SSNMR spectrum of the blank GSH/pH-NS is shown in Figure 2A. Several large signals at $168.2 \mathrm{ppm}$ (carboxylic/ ester groups), 130.9 ppm (aromatic $\mathrm{C}$ atoms), $100.9 \mathrm{ppm}$ (O-C-O of the $\beta-\mathrm{CDs}, 71.6 \mathrm{ppm}$ (C-O of the $\beta$-CDs and 2-hydroxyethyl disulfide) and lastly at $30.2 \mathrm{ppm}$ (C-S belonging to 2-hydroxyethyl disulfide) were observed.

Then, a blank GSH-NS nanosuspension was prepared to obtain a nanoformulation for drug loading. A high pressure homogenization (HPH) step was performed to obtain NS with sizes in the nanometer range and a nearly homogeneous particle distribution. The average diameter of the blank GSH/ pH-NS nanoformulation was approximately $200 \mathrm{~nm}$.
The zeta potential of the blank GSH/pH-NS was approximately $-30 \mathrm{mV}$, which was high enough to ensure the physical stability of the colloidal nanoformulations and avoid aggregation. The SLs were readily incorporated into the GSH/pH-NS. The drug loading capacity was $13.9 \%$ for MEB55 and 15.4\% for ST362, and the encapsulation efficiency was $88.7 \%$ and $96.5 \%$, respectively. The incorporation determined a huge increase of the SL apparent solubility. Indeed, the aqueous solubility of free MEB55 and ST362 was less than $0.2 \mu \mathrm{g} / \mathrm{mL}$ and $0.5 \mu \mathrm{g} /$ $\mathrm{mL}$, respectively, while an SL concentration of $1.5 \mathrm{mg} / \mathrm{mL}$ was achieved for both the compounds when incorporated into the $\mathrm{GSH} / \mathrm{pH}-\mathrm{NS}$.

A comparison of the physical and chemical characteristics of the MEB55 and ST362-loaded GSH/pHNS relative to the blank GSH/pH-NS is shown in Table 1. MEB55 and ST362 loading resulted in an approximately $8 \%$ increase in the size of the GSH/pH-NS and an approximately $15 \%$ decrease in the negative surface charge.

We analyzed the size and morphology of the blank and loaded GSH/pH-NS using transmission electron microscopy (TEM). The GSH/pH-NS had spherical shapes and the sizes were in the nanoscale range (Figure 3A). No changes in morphology were
A

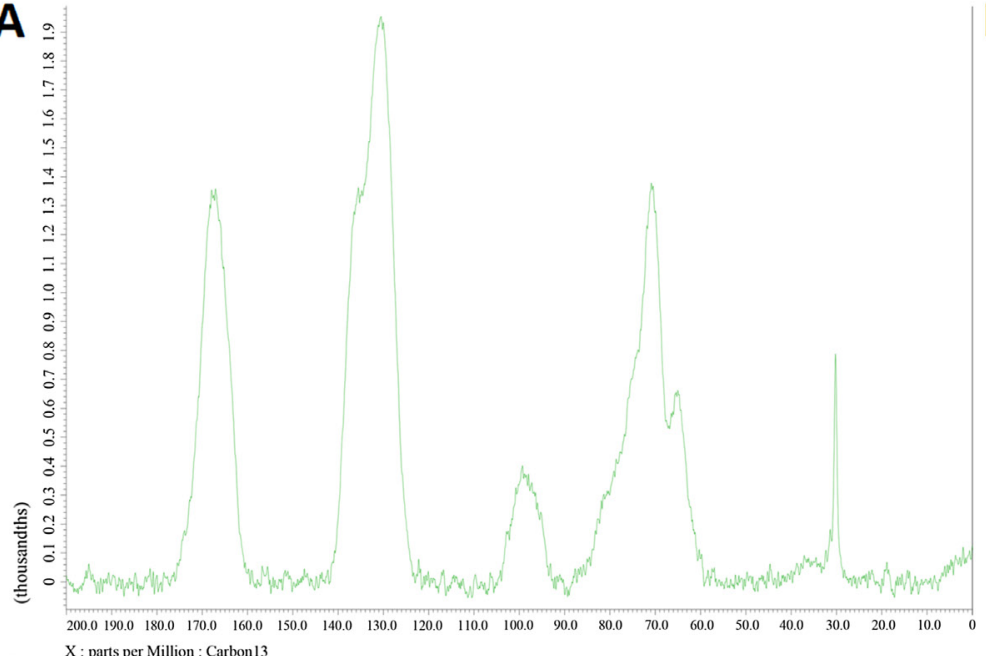

$\mathrm{X}$ : parts per Million : Carbon 13

C

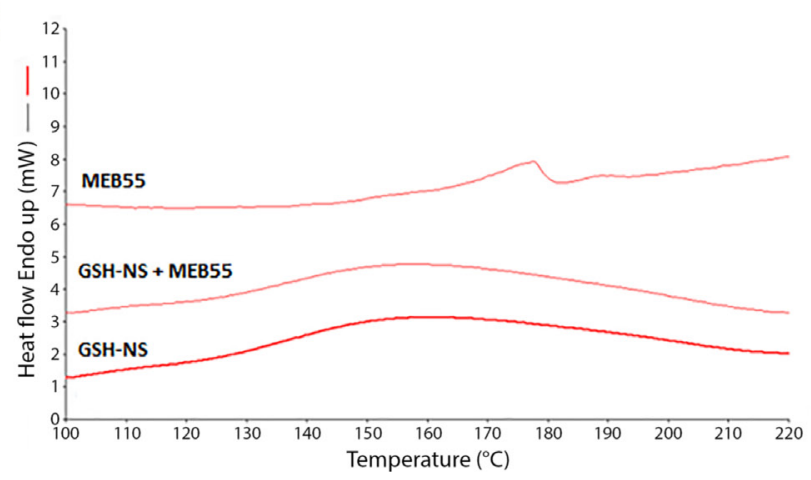

B

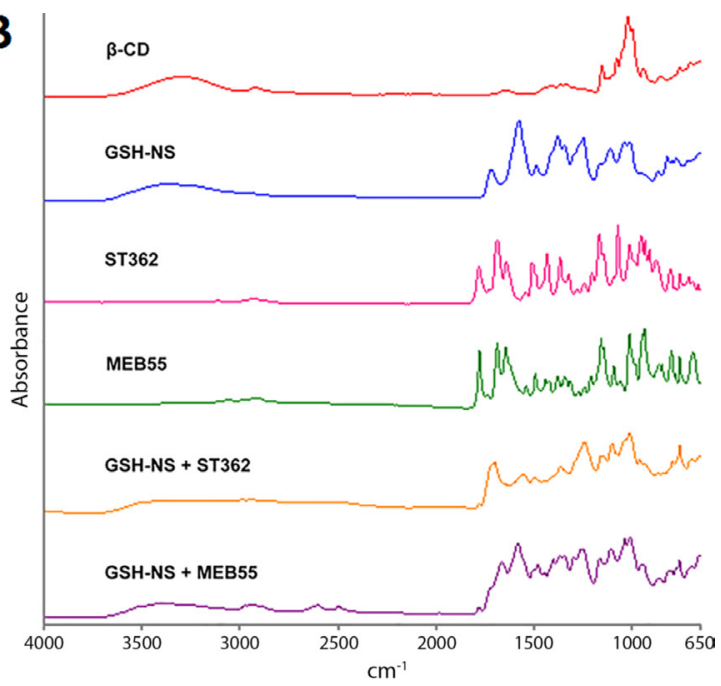

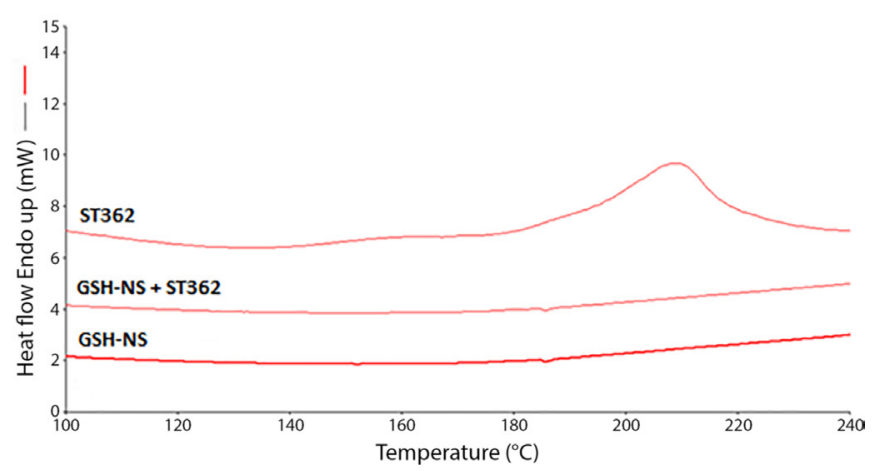

Figure 2: (A) ${ }^{13} \mathrm{C} \mathrm{CP} / \mathrm{MAS}$ NMR (40-200 ppm) spectra of blank GSH/pH-NS, acquired with a spinning rate of $20 \mathrm{kHz}$ at room temperature; (B) FTIR spectra of MEB55- and ST362-loaded GSH/pH-NS; (C) DSC thermograms of MB55- and ST362-loaded GSH/pH-NS. 
Table 1: Comparison of the physical and chemical characteristics of blank and SL-loaded GSH/ pH-NS

\begin{tabular}{lccc}
\hline Formulation & Average diameter \pm SD $(\mathbf{n m})$ & Polydispersity index & Zeta potential \pm SD $(\mathbf{m V})$ \\
\hline Blank GSH/pH-NS & $203.4 \pm 12.3$ & $0.20 \pm 0.01$ & $-31.5 \pm 3.8$ \\
ST362-loaded GSH/pH-NS & $219.8 \pm 18.7$ & $0.22 \pm 0.02$ & $-26.3 \pm 2.5$ \\
MEB55-loaded GSH/pH-NS & $217.3 \pm 23.2$ & $0.21 \pm 0.02$ & $-27.6 \pm 2.3$ \\
\hline
\end{tabular}

observed after incorporation of the SLs into the GSH/ pH-NS. Figure 3B reports TEM image of MEB55-loaded GSH/pH-NS. We next performed Fourier transform infrared spectroscopy (FTIR) and differential scanning calorimetry (DSC) to evaluate physical interactions between the SLs and the GSH/pH-NS. The FTIR spectra of the free SLs, SL-loaded GSH/pH-NS, and blank GSH/pH-NS are shown in Figure 2B. In addition to the fingerprint region, SLs exhibit intense absorption peaks in the $1800-1600 \mathrm{~cm}^{-1}$ range. The first peak $\left(1780 \mathrm{~cm}^{-}\right.$ $\left.{ }^{1}\right)$ is due to the stretching of $\mathrm{C}=\mathrm{O}$ bond in the D-ring of MEB55 and ST362, whereas the following bands derive from the absorption of $\mathrm{C}=\mathrm{O}$ in the $\mathrm{C}$-ring and $\mathrm{C}$ $=\mathrm{C}$ bonds adjacent to nitrogen and oxygen atoms. Less intense peaks appearing around $2900 \mathrm{~cm}^{-1}$ are associated with $\mathrm{C}-\mathrm{H}$ stretching in $\mathrm{CH}, \mathrm{CH}_{2}$ and $\mathrm{CH}_{3}$ groups. We observed changes and shifts in the MEB55 and ST362 peaks following incorporation into the GSH/pH-NS, reflecting the presence of physical interactions between the SLs and the GSH/pH-NS matrix. DSC thermograms confirmed that the SLs were incorporated into the GSH/ pH-NS (Figure 2C). The endothermic melting peaks of MEB55 and ST362 $\left(178^{\circ} \mathrm{C}\right.$ and $210^{\circ} \mathrm{C}$, respectively) were completely absent in the melting curves of the SL- loaded GSH/pH-NS, indicating the SLs were molecularly dispersed within the nanostructure of the GSH/pH-NS, and did not form crystals. Conversely, freeze-drying the free SLs resulted in the formation of a crystalline powder with a detectable melting peak at the fusion temperature of SLs (data not shown). These results were consistent with those of previous studies of other NS [36-39].

Taking into account the stability issues of SL in solution, we analyzed the stability of the SLs dissolved in either acetone or $\mathrm{N}$-methylpirrolidone- $0.9 \% \mathrm{NaCl}$ solution, and when loaded in the GSH/pH-NS. Encapsulation of the SLs in the GSH/pH-NS enhanced the chemical stability of the compounds compared to free SLs in the two solutions (Figure 4A, 4B). The concentrations of the SLs encapsulated in the GSH/pH-NS were $1.5 \mathrm{mg} /$ $\mathrm{mL}$ for up to 3 months stored at $4^{\circ} \mathrm{C}$. In contrast, a $22 \%$ decrease in the concentration was observed for free SLs in solution, which was indicative of reduced chemical stability. Moreover, we evaluated the physical stability of the GSHNS nanoformulations. We monitored the average diameter and zeta potential of the GSH/pH-NS in cell culture medium and $0.9 \% \mathrm{NaCl}$ solution over 24 hours. The $\mathrm{GSH} / \mathrm{pH}-\mathrm{NS}$ were stable in cell culture medium for up to $24 \mathrm{~h}$, which was the timeframe used in our biological assays (Figure 4C, 4D).
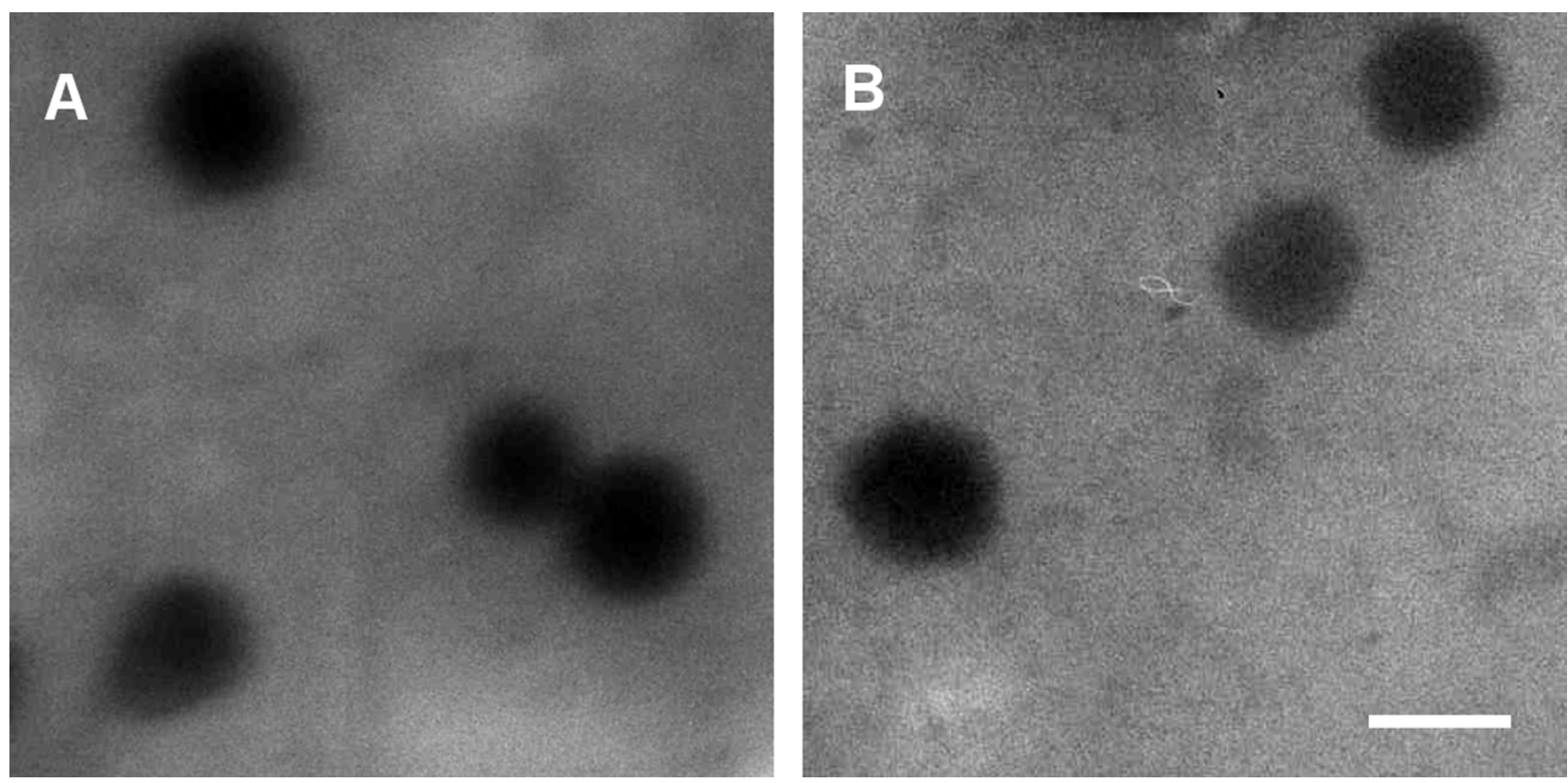

Figure 3: TEM images of (A) blank GSH/pH-NS and (B) SL-loaded GSH/pH-NS (scale bar = $200 \mathrm{~nm}$ ). 
We next investigated the GSH- and pH-dependent release of the SLs from the GSH/pH-NS. The in vitro release kinetics of ST362 and MEB55 from the GSH/ $\mathrm{pH}-\mathrm{NS}$ in the presence of increasing GSH concentrations $(1,5$, and $20 \mathrm{mM})$ are shown in Figure $5 \mathrm{~A}$ and $5 \mathrm{~B}$, respectively. We observed a slow and constant release profile with no initial burst effect for both the ST362- and MEB55-loaded GSH/pH-NS. SL-release from the GSH/ $\mathrm{pH}-\mathrm{NS}$ was dependent upon the GSH concentration in the receiving phase. The cumulative percent release was 2.5 -fold higher in the presence of $20 \mathrm{mM}$ GSH after 6 hours. We also analyzed the release kinetics of ST362 and MEB55 in the presence of $1 \mathrm{mM} \mathrm{GSH}$ at pH 5.5 and pH 7.4 (Figure 5C and 5D, respectively). Interestingly, we observed a $\mathrm{pH} /$ redox dual-responsive release profile for both SLs. The cumulative percent release of the SLs from the GSH/pH-NS was approximately $4 \%$ at $\mathrm{pH} 7.4$ compared to $12 \%$ at $\mathrm{pH} 5.5$ after 6 hours, indicating release was enhanced at acidic $\mathrm{pH}$.

We next evaluated the effects of MEB55- and ST362-loaded GSH/pH-NS on the growth of DU145 and $\mathrm{PC}-3$ prostate cancer cells in culture. These cell lines displayed high and low GSH content, respectively [35]. Cell viability was analyzed after treatment of the cells for $24 \mathrm{~h}$ with a range of concentrations $(0.1-10 \mu \mathrm{M})$ of free SLs or SL-loaded GSH/pH-NS using MTT assays. We found that MEB55 (both free and loaded in GSH/ $\mathrm{pH}-\mathrm{NS}$ ) inhibited the proliferation of both cell types to a greater extent than ST362. Both SL-loaded GSH/pHNS inhibited the proliferation of the DU145 cells (high
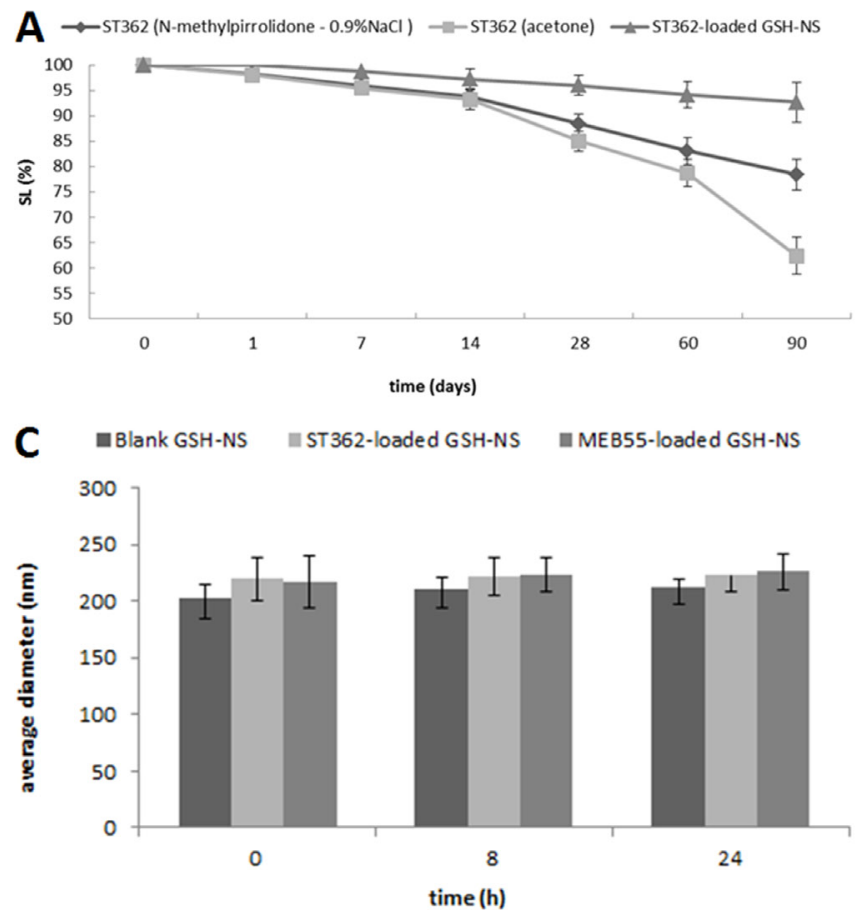

GSH content) to a greater extent than the corresponding free drugs at all concentrations analyzed (Figure 6). In contrast, the SL-loaded $\mathrm{GSH} / \mathrm{pH}-\mathrm{NS}$ did not show statistically different effects on cell proliferation in PC-3 cells (low GSH content), compared to the corresponding free drugs, suggesting that the activity of the GSH/pH-NS is dependent upon the intracellular GSH content. The $\mathrm{IC}_{50}$ values for the free SLs and SL-loaded GSH/pH-NS are shown in Table 2.

The blank GSH/pH-NS did not demonstrate any toxicity, even at the highest doses (data not shown), consistent with a previous study [35].

To affirm the anticancer activity further, lactate dehydrogenase (LDH) assays were performed on DU145 and PC3 cells. Additionally, we analyzed other two colon cell lines, HCT116 and HT29 cells, which displayed high and low GSH concentrations, respectively [35], and compared them to normal NIH$3 \mathrm{~T} 3$ fibroblasts. LDH release was observed in the culture medium of cells treated with SL formulations. The blank GSH/pH-NS did not show any toxicity, even at the highest concentrations (data not shown). The results indicated the efficacy of SL in inducing cell death by damaging the cell membrane. The percent LDH release was higher in DU-145 and HCT-116 cells treated with the SL-loaded GSH/pH-NS compared to free SL-treated cells (Figure 7).

The percentage of LDH release in HT29 cells (low GSH content) was higher after treatment with free SLs compared to SL-loaded GSH/pH-NS, indicating reduced

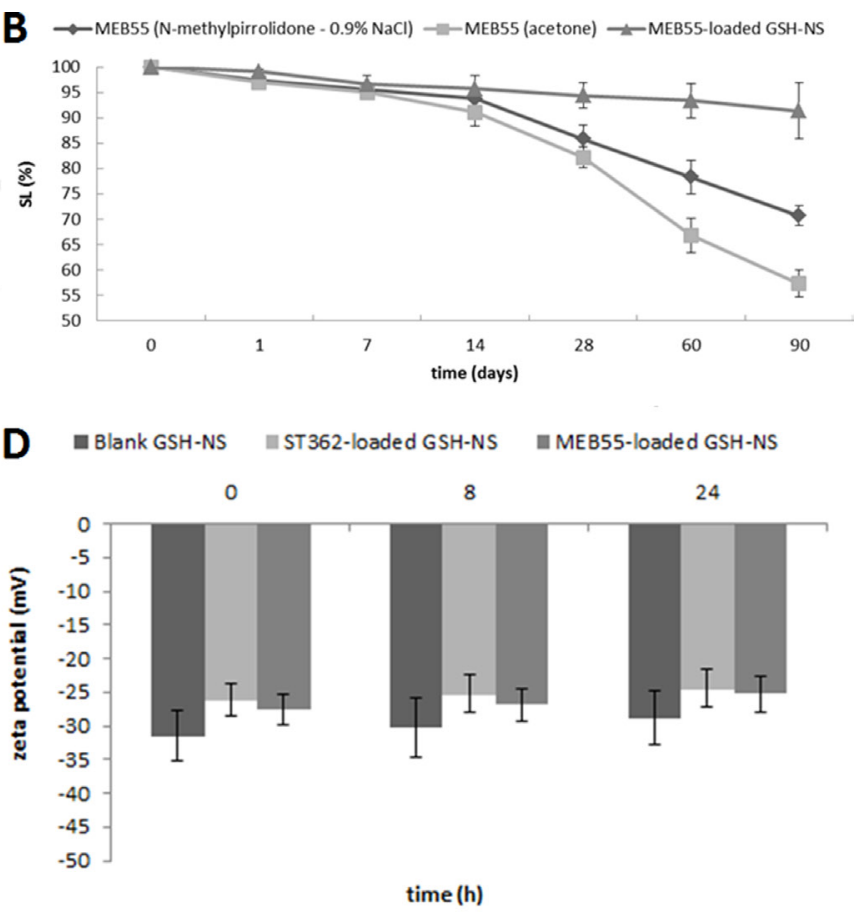

Figure 4: In vitro stability studies. Chemical stability over time of (A) ST362 and (B) MEB55; (C) Average diameters and (D) Z-potentials of $\mathrm{GSH} / \mathrm{pH}-\mathrm{NS}$ formulations incubated in cell culture medium $(t=0,8$ and 24 hours). Each value represents the mean $\pm \mathrm{SD}$ of 3 experiments. 
Table 2: $\mathrm{IC}_{50}$ values for free SLs and SL-loaded GSH/pH-NS in PC-3 and DU145 prostate cancer cells

\begin{tabular}{ccc}
\hline & PC-3 & DU145 \\
\cline { 2 - 3 } Formulation & $\mathbf{I C}_{\mathbf{5 0}}(\boldsymbol{\mu M})$ & $\mathbf{I C}_{\mathbf{5 0}}(\boldsymbol{\mu M})$ \\
\hline MEB55 & $6.5 \pm 0.8$ & $6.4 \pm 0.2$ \\
MEB55-loaded GSH/pH-NS & $3.5 \pm 1.2$ & $2.4 \pm 0.2^{*}$ \\
ST362 & $19 \pm 2.2$ & $15 \pm 0.5$ \\
ST362-loaded GSH/pH-NS & $12 \pm 1.8$ & $6.0 \pm 0.3^{*}$ \\
\hline${ }^{*} p<0.05$. & &
\end{tabular}

${ }^{*} p<0.05$.

compound delivery from the nanosponges in these cells after $24 \mathrm{~h}$. Minimal SL release was observed in PC-3 cells (low GSH content). Finally, neither the free SLs nor the SL-loaded GSH/pH-NS were capable of inducing LDH release in normal NIH-3T3 cells.

We further confirmed the inhibitory effects of the SL-loaded GSH/pH-NS on cell proliferation using colony formation assays. This assay showed that SLs loaded in NS are able to reduce cell proliferation and that the antiproliferative effect was affected by the intracellular GSH content.

Clonogenic assay results demonstrated that the inhibition of cell proliferation induced by SL-loaded GSH/pH-NS was in agreement with LDH release (Figures 7 and 8 ). Indeed, only cells with intact membranes and reproductive capacity were able to form colonies.
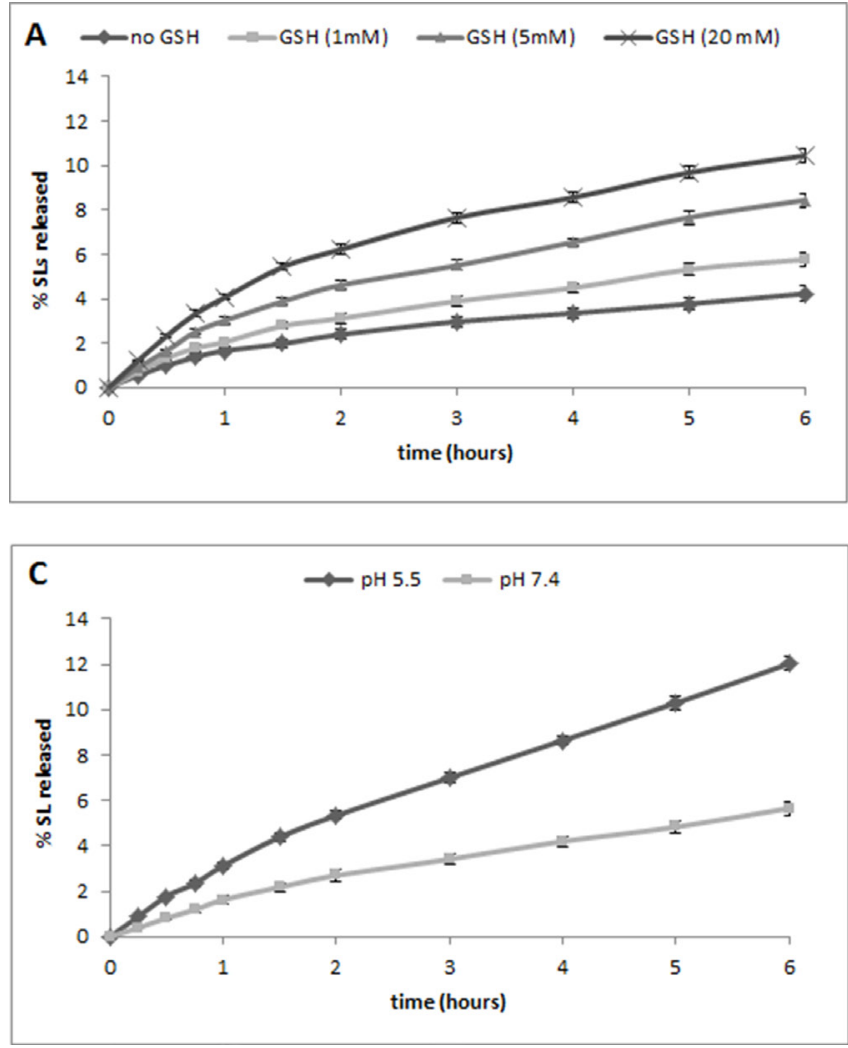

We next investigated whether the inhibitory effects of the SL-loaded GSH/pH-NS on the growth of PC-3 and DU145 cells were due to apoptosis by staining the cells with Annexin $\mathrm{V}$ after treatment with free SLs or SL-loaded GSH/pH-NS $(0.1-5 \mu \mathrm{M})$ for $24 \mathrm{~h}$ (Figure 9). The number of Annexin V-positive cells was higher among DU145 cells treated with the SL-loaded GSH/pH-NS compared to free SL treated cells (Figure 9). In contrast, there were few Annexin V-positive PC-3 cells following treatment with free SLs and SL-loaded GSH/pH-NS, which likely reflected reduced release of SLs in these cells. We observed no differences in cell death between DU145 and PC3 cells treated with free MEB55 or ST362. These data indicated that the release of the SLs from the GSH/pH-NS was stimulus-dependent.

We previously demonstrated that doxorubicinloaded GSH/pH-NS were rapidly internalized by cancer
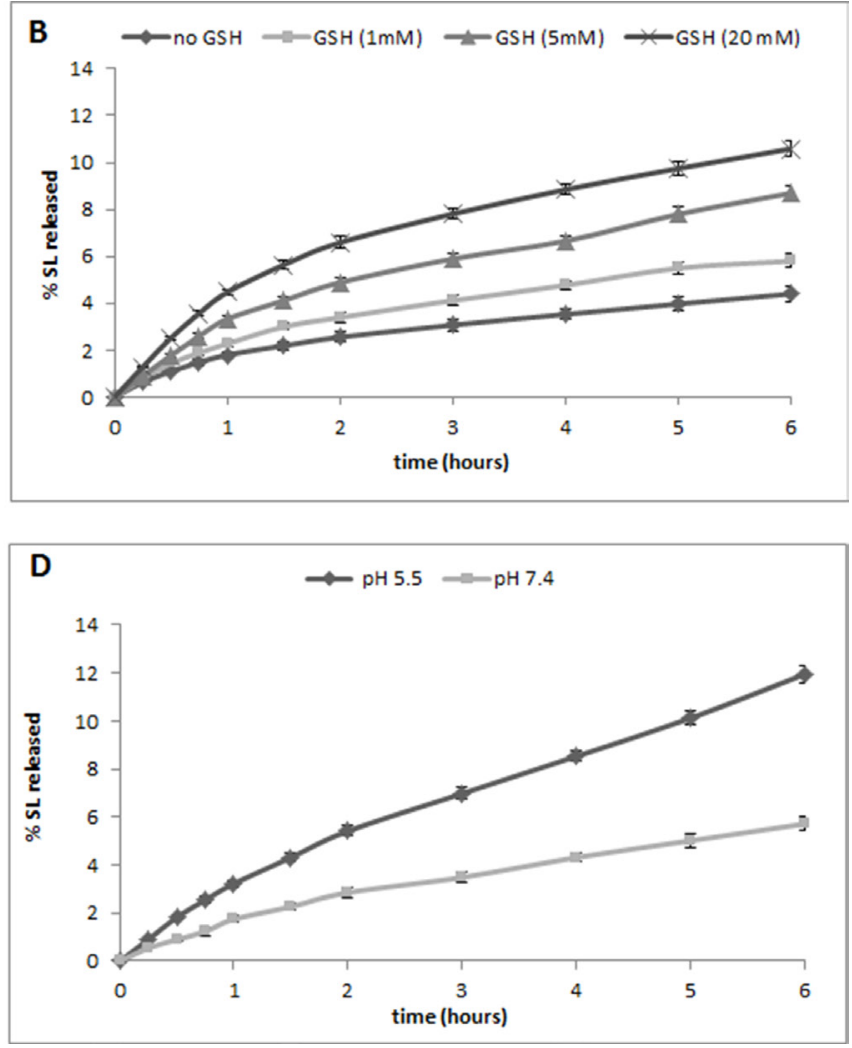

Figure 5: In vitro release kinetics of (A) ST362 and (B) MEB55 from GSH/pH-NS in the presence of increasing GSH concentrations (1, 5, and $20 \mathrm{mM}$ ), and of (C) ST362 and (D) MEB55 at pH 5.5 and 7.4 in the presence of $1 \mathrm{mM} \mathrm{GSH}$. 
cells, exploiting the intrinsic fluorescence of doxorubicin [35]. Here, GSH/pH-NS were loaded with a fluorescent marker, 6-coumarin, being an insoluble molecule in water [25]. Previously, we demonstrated that it was easily incorporated in the nanosponge matrix and was not released overtime. As a consequence, the internalization referred to the fluorescent nanoparticles. Cellular uptake of the fluorescently labelled GSH/pH-NS was analyzed in PC3 and DU145 cells after treatment for $4 \mathrm{~h}$ at either at $4^{\circ} \mathrm{C}$ or $37^{\circ} \mathrm{C}$ by flow cytometry (Figure 10 ). The percentage of fluorescent cells was dependent on the dose of the GSH/pH-NS and was higher after incubation at $37^{\circ} \mathrm{C}$ compared to $4^{\circ} \mathrm{C}$ in the DU145 cells. In contrast, the fluorescence was lower at both temperatures in PC-3 compared to DU145 cells (Figure 10). We evaluated the release kinetics of 6-coumarin from the GSH/pH-NS and observed a negligible release in the receiving phase after $24 \mathrm{~h}$ in the absence of GSH, as well in the presence of low GSH (data not shown). Fluorescence microscopy images demonstrating accumulation of the fluorescently labelled GSH/pH-NS in PC-3 and DU145 cells are shown in Figure 11.

We confirmed the intracellular accumulation of SLs in PC-3 and DU145 cells by measuring the SL concentration in cell lysates $24 \mathrm{~h}$ after incubation at $37^{\circ} \mathrm{C}$ with $0.1-10 \mu \mathrm{M}$ free ST362 or MEB55 or the SL-loaded GSH/pH-NS using high performance liquid chromatography (HPLC) (Figure 11). Accumulation of the GSH/pH-NS was observed in all cells. The free drug content was higher in DU145 cells incubated with SL-loaded GSH/pH-NS than in cells incubated with the free SLs. At a concentration of $10 \mu \mathrm{M}$, the intracellular
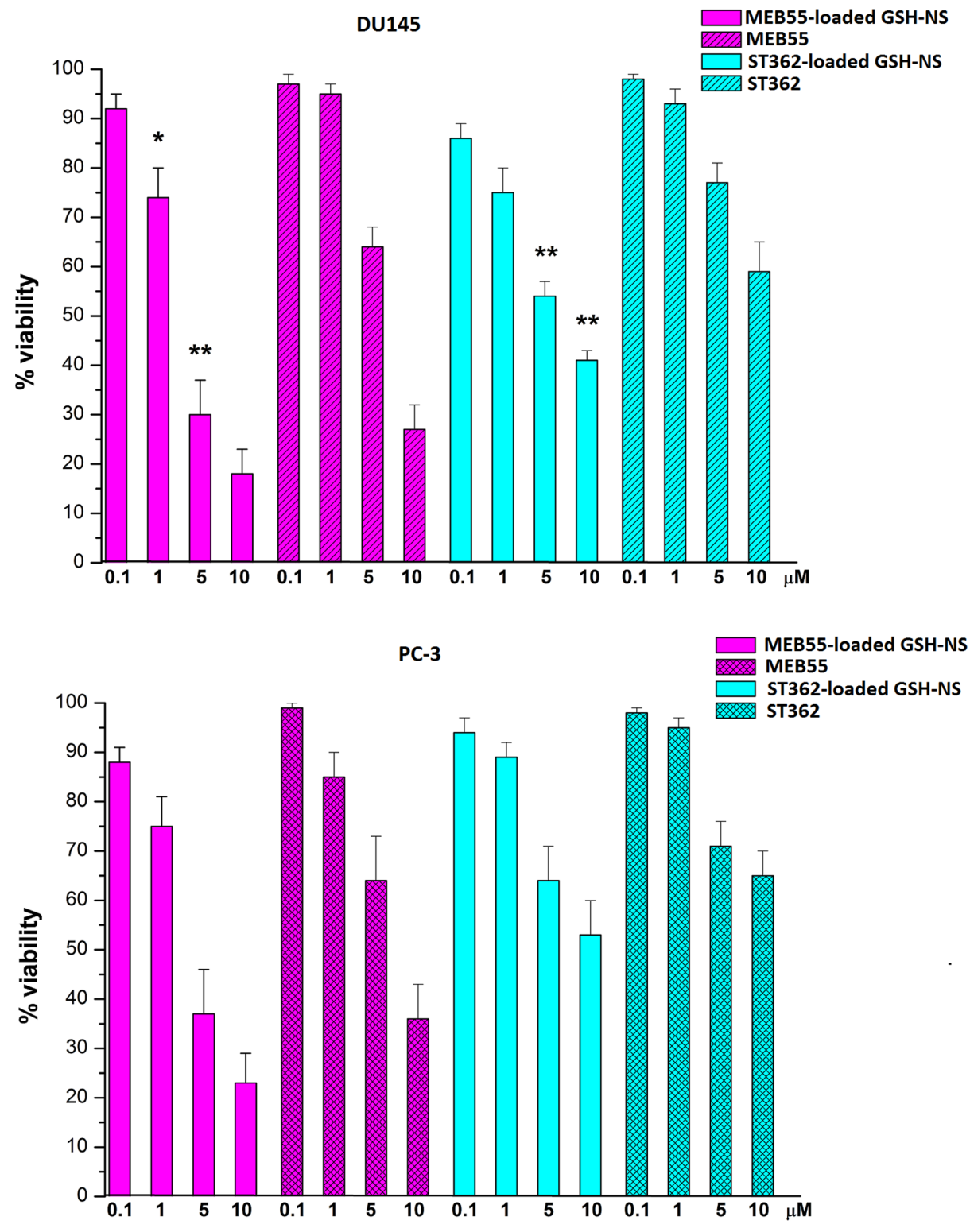

Figure 6: Analysis of cell viability $24 \mathrm{~h}$ after treatment of prostate cancer cells with free SLs or SL-loaded GSH/pH-NS. The data are expressed as the percentage of viable cells relative to controls. " $p<0.05$. 
concentrations of MEB55 or ST362 were 1.52 and 2.68fold higher, respectively, in cells treated with SL-loaded $\mathrm{GSH} / \mathrm{pH}-\mathrm{NS}$ relative to cells treated with free SLs. Thus, the GSH/pH-NS enhanced the accumulation of the SLs in prostate cancer cells.

\section{DISCUSSION}

We developed novel GSH/pH-NS, responsive to $\mathrm{pH}$ and redox stimuli, to deliver two SL analogues (MEB55 and ST362) to prostate cancer cells with precise spatio-temporal control. The rationale of the nanoparticle design with multiple responsiveness was to provide 'on demand' targeted SL release as a function of the intracellular microenvironment. To our knowledge, this is the first work concerning the formulation of SLs in a nanocarrier, although Pollock et al. [11] previously demonstrated the efficacy of MEB55 and ST362 solubilized in acetone in primary prostate cancer cells.

We hypothesized that the incorporation of SLs into the GSH/pH-NS might circumvent issues with solubility and stability in aqueous solutions at physiological $\mathrm{pH}$. Additionally, the low selectivity of a SL solution either in the therapeutic action or in the spatial distribution may lead to toxicity and low effectiveness. It is worth noting that
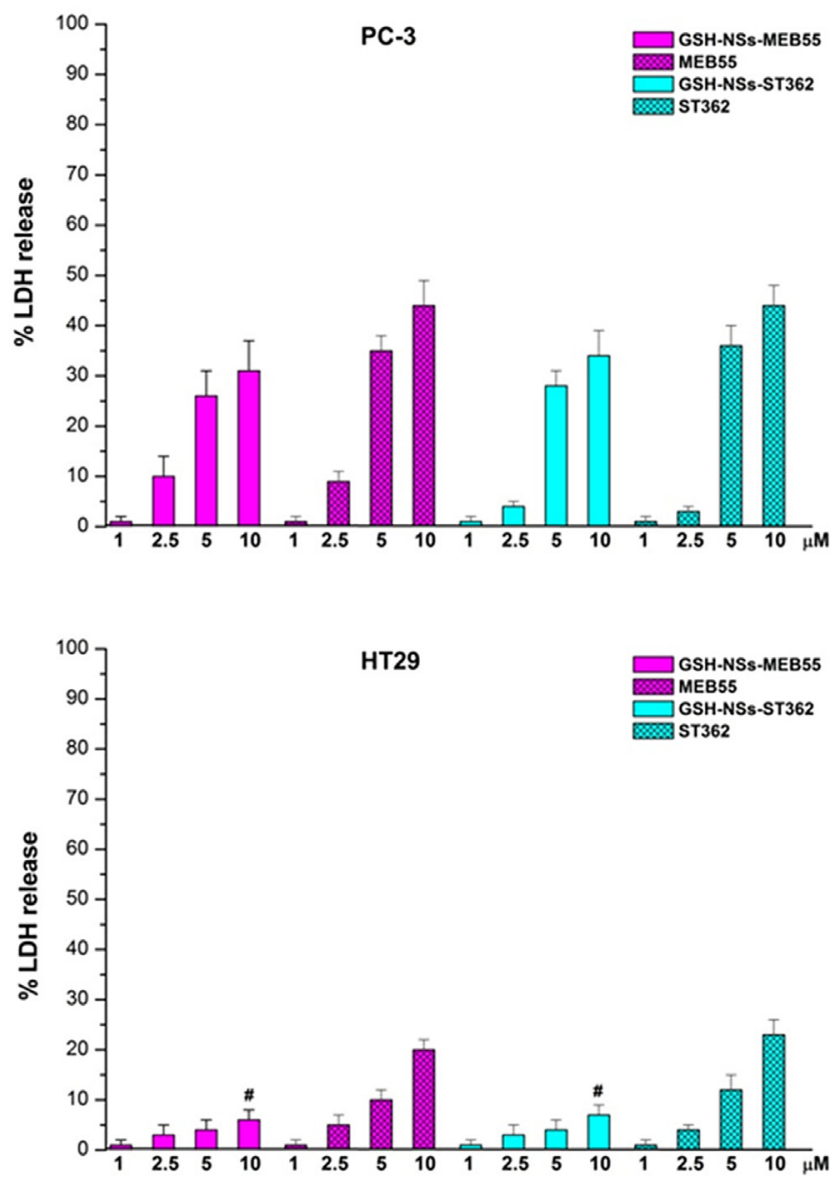

the use of a drug within a nanodelivery system presents significant advantages versus normal cells. One of them concerns the capability to enhance the pharmacokinetics and biodistribution profiles, thereby improving drug efficacy and reducing side effects $[40,41]$. GSH/pH-NS might modify the biodistribution and intracellular release kinetics of the incorporated SLs. Interestingly, previous in vivo experiments in animal models demonstrated that NS are able to modify the pharmacokinetics parameters of the loaded drugs [26, 38, 42]. Very recently, GSHNS encapsulating doxorubicin exhibited a prolonged circulation time after intravenous administration to rats and were able to extravasate in tumor tissues exploiting the Enhanced Permeability and Retention (EPR) effect [35]. These findings motivate the encapsulation of SL in this type of nanoparticles.

We found that both MEB55 and ST362 were molecularly loaded into the GSH/pH-NS in a great extent. The incorporation avoided the compound crystallization as showed by DSC analysis. The SLs could be incorporated into the $\mathrm{GSH} / \mathrm{pH}-\mathrm{NS}$ as either inclusion or non-inclusion complexes, and they could interact with multiple sites in the nanosponge matrix, including the hydrophobic $\beta-C D$ cavities and hydrophilic nanochannels of the polymeric network [20]. In addition, the slow in vitro release kinetics and the absence of an initial burst effect were suggestive
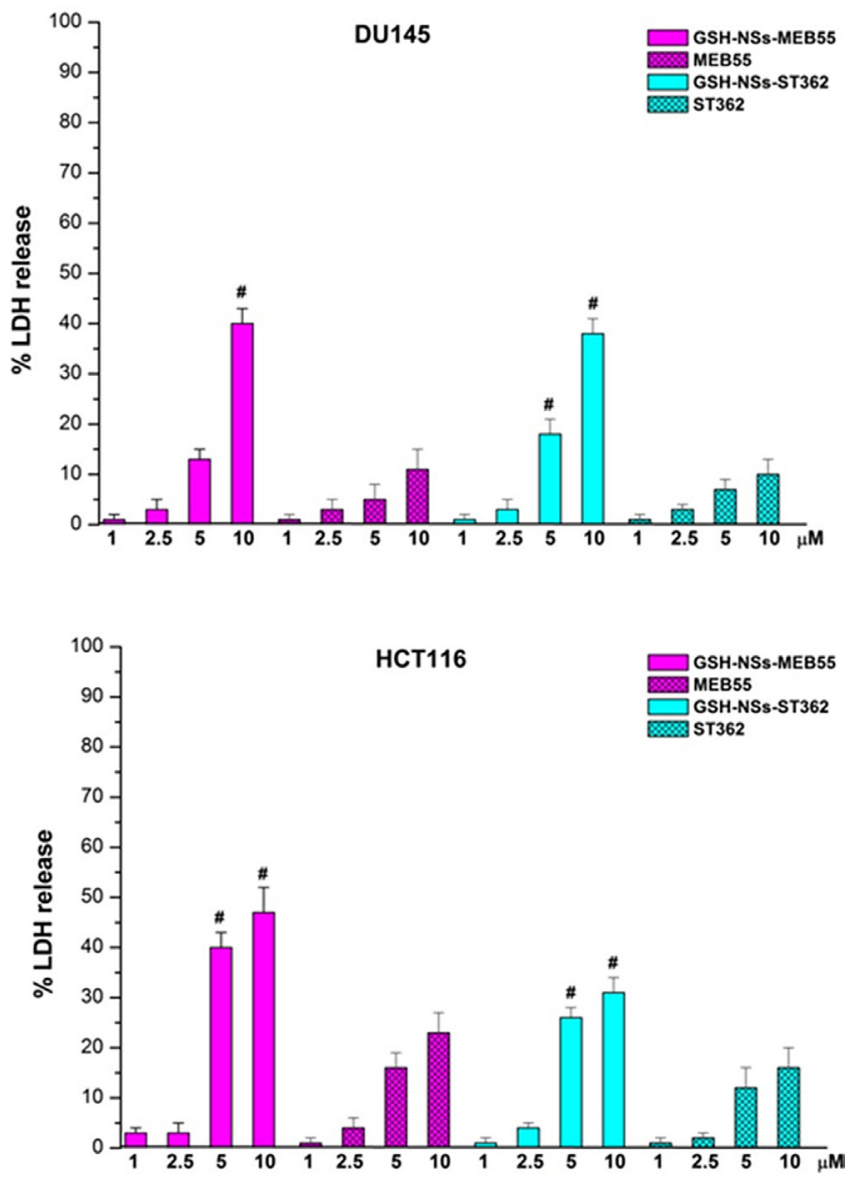

Figure 7: LDH release after treatment of the indicated cell lines with SLs or SL-loaded GSH/pH-NS for 24 h. ${ }^{*} p \leq 0.05$. 
of strong physical interactions between the SLs and the matrix of the GSH/pH-NS. The encapsulation of the SLs in the GSH/pH-NS protected them from chemical degradation and markedly increased the aqueous solubility. A thousand-fold enhancement of SL apparent solubility was reached. Indeed, due to compound loading, the solubility increased from $0.5 \mu \mathrm{M}$ and $1.1 \mu \mathrm{M}$ for
MEB55 and ST362, respectively, to about $3 \mathrm{mM}$. These results are consistent with those of previous studies of other compounds [36-37]. The physical and chemical characteristics of nanoparticles (e.g. size, surface charge) are important to determine particle to cell interactions. They are crucial parameters in developing efficient nanomedicine with minimal toxicity. Specifically, the
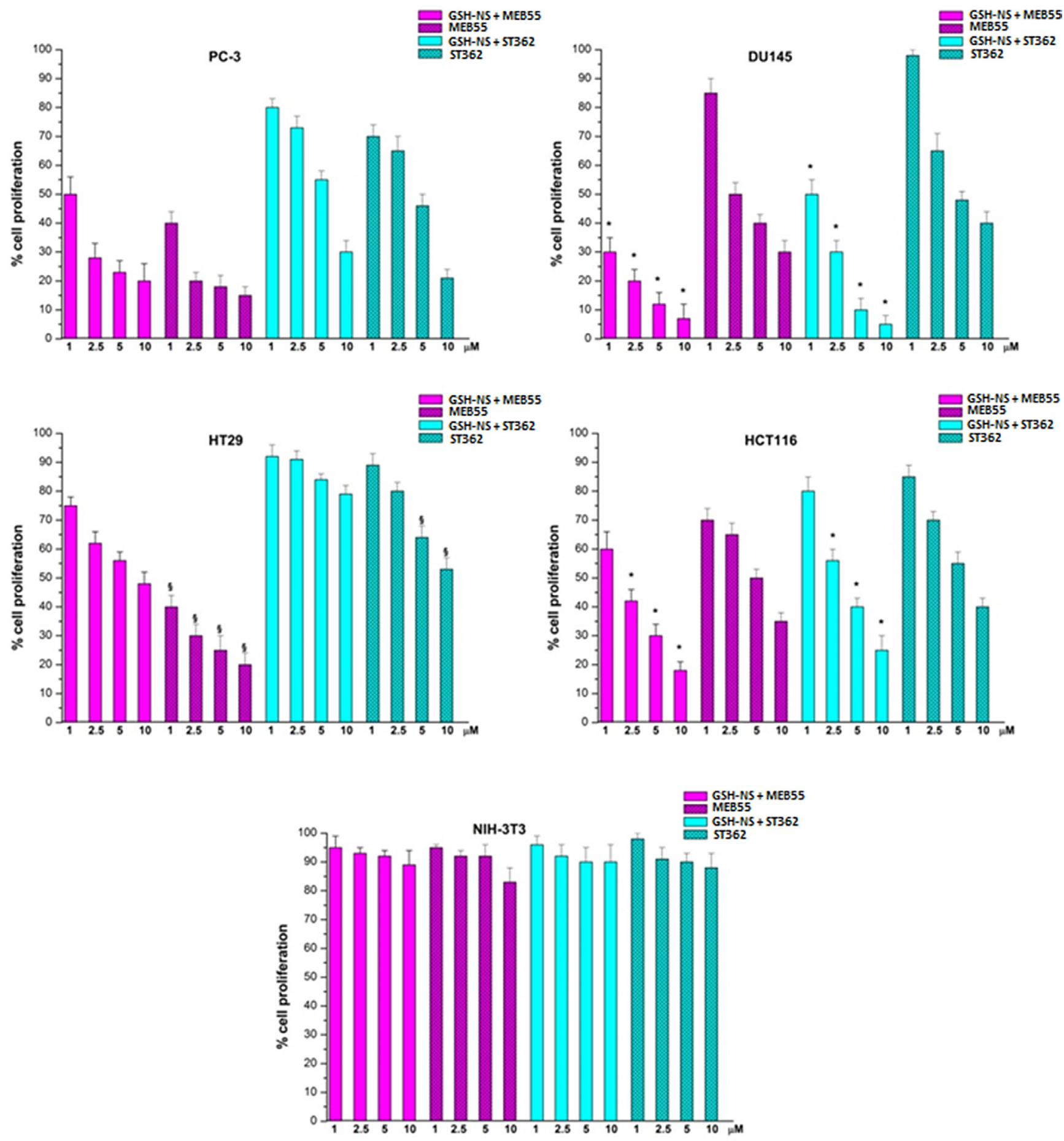

Figure 8: Colony formation assays of the indicated cell lines following treatment with SLs or SL-loaded GSH/pH-NS. ${ }^{*} p \leq 0.05$ indicates a significant difference between cells treated with free SLs vs. SL-loaded GSH/pH-NS at the same concentrations. ${ }^{\S} p \leq 0.05$ indicates a significant difference between cell lines treated with the same concentrations of SL-loaded GSH/pH-NS. Data are expressed as the percentage of cell proliferation. 
size of nanoparticles can impact cellular uptake [43]. The nanoscale range is advantageous for drug delivery because nanoparticles are more readily internalized by cells compared to microparticles [35, 44-45].

Particle size can also influence the pathway of cellular uptake. In the literature it is reported that spherical particles with size $\leq 200 \mathrm{~nm}$ enter the cell through clathrin-mediated cell uptake, while by increasing size to $500 \mathrm{~nm}$, caveolae-mediated process is the predominant phenomenon in the cell internalization [46].
Based on these premises, the sizes of GSH/pH-NS were purposely tuned, using a HPH step in the preparation process, to obtain almost uniform small nanoparticles in the nanometer order of magnitude. We generated SL-loaded GSH/pH-NS with an average diameter of approximately $200 \mathrm{~nm}$, which might facilitate rapid internalization into cancer cells and might exploit the EPR effect after administration [15].

In addition, surface charges are related to various biological performances of the nanoparticles [47]. The
DU145

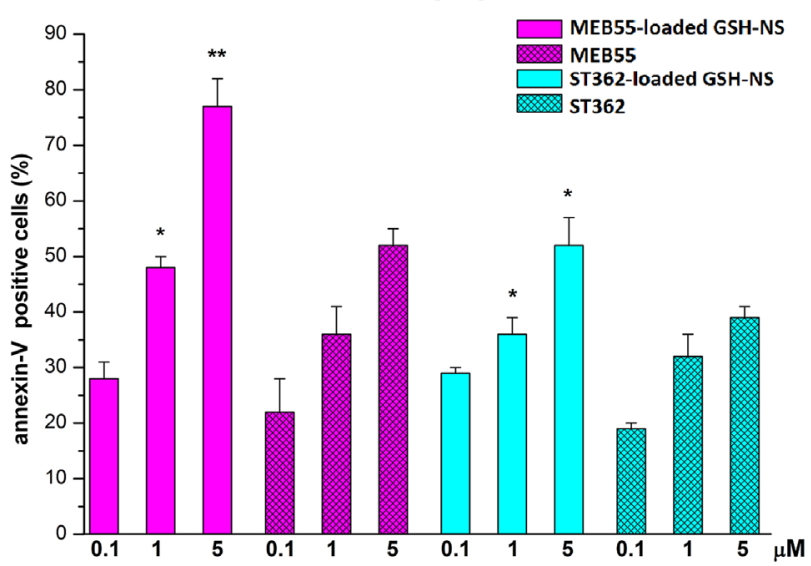

PC-3

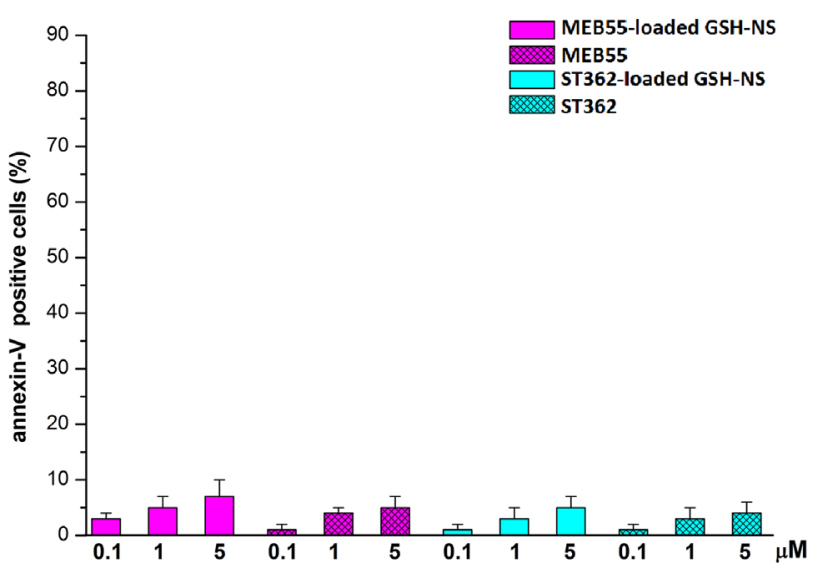

Figure 9: Levels of Annexin-V-positive cells after treatment for 24 h with either free SL or SL-loaded GSH/pH-NS. Annexin-V-positive DU-145 (left panel) and PC-3 (right panel) cells. The results are expressed as the percentage of positive cells ${ }^{*} p<0.05$; ${ }^{* * *} p<0.01$.
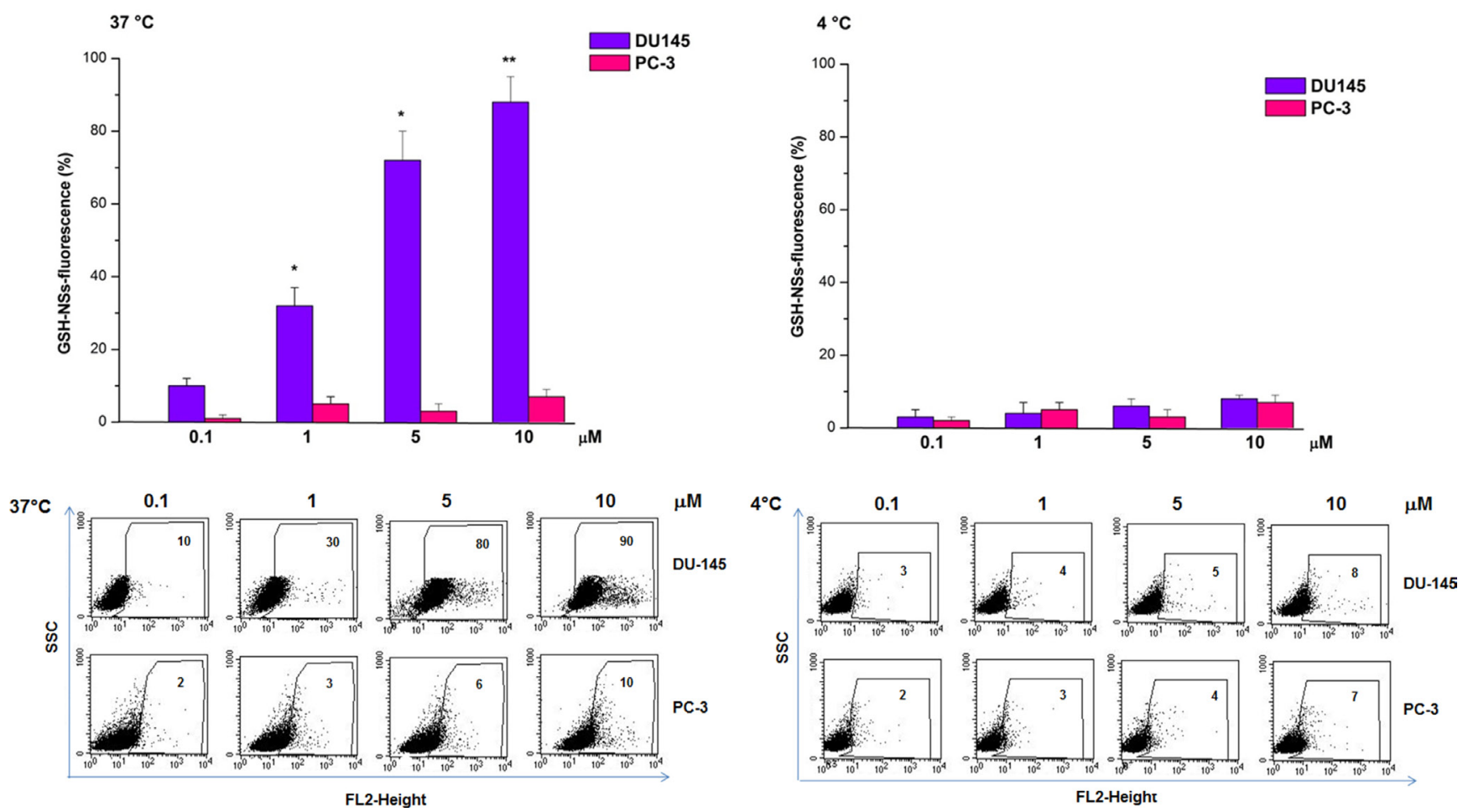

Figure 10: Flow cytometry analysis of the uptake of the GSH/pH-NS by prostate cancer cells. DU-145 or PC-3 cells treated with the GSH/pH-NS at $37^{\circ} \mathrm{C}$ (left panel) or $4{ }^{\circ} \mathrm{C}$ (right panel). The data are expressed as the mean $\pm \mathrm{SEM}$ for four independent experiments $\left({ }^{* *} p<0.01,{ }^{*} p<0.05\right.$ compared to controls, paired $T$-test). Fluorescence activated cell sorting plots represent a single experiment. 
negative charge of the GSH/pH-NS can play a role in cellular uptake. It has been demonstrated that an increase in surface charge, either positive or negative, can enhance particle uptake compared to uncharged nanoparticles [43].

Stimuli responsive nanocarriers for anticancer drugs have attracted much research. They were designed to be inert during circulation, until they reach tumor tissue where they can receive the stimulus to release the drug. The intracellular SL release might be triggered by cellular environment. Various studies have shown that the intracellular $\mathrm{pH}$ is lower in cancer compared to normal cells [48]. Therefore, several $\mathrm{pH}$-sensitive nanocarriers have been developed in order to deliver drugs under acidic conditions (i.e. $\mathrm{pH}$ 5.5 and 4.5 , which correspond to the $\mathrm{pH}$ of endosomes and lysosomes, respectively) [49]. Moreover, the tumor reductive microenvironment, due to the higher GSH concentration than normal cells, is a feature for designing tumor-responsive nanotherapeutics. Particularly, dual redox and $\mathrm{pH}$-responsive nanocarriers might have a great potential in the controlled release of a drug as a function of cellular environment. The presence of various targeting strategies in a drug-loaded nanomedicine is one of the novel approach to achieve combination therapy [50]. Dual redox/pH sensitive nanosponges are "smart" drug delivery systems designed to have high serum stability in physiological conditions and accumulate by EPR effect in the tumor microenvironment with peculiar biological parameters (i.e. low $\mathrm{pH}$ value and high GSH concentration). The dual stimuli-responsive GSH/ $\mathrm{pH}-\mathrm{NS}$ can provide a controlled drug release at a target site [51]. Interestingly, the in vitro release profiles from $\mathrm{GSH} /$ $\mathrm{pH}-\mathrm{NS}$ were $\mathrm{pH}$ - and GSH-dependent. We found that the SLs were released from the GSH/pH-NS faster at $\mathrm{pH} 5.5$ compared to $\mathrm{pH} 7.4$ in the presence of high concentrations of GSH. These results are consistent with the chemical structures of the GSH/pH-NS, which contain free carboxylic groups in the polymer network and disulfide bridges that can be reduced in a reducing environment thereby favoring SL release. The free carboxylic group of the pyromellitic dianhydride, which was used as a cross-linker of $\beta-C D$, is only partly dissociated at $\mathrm{pH}$ 5.5. This results in reduced electrostatic interactions and enables release of the SLs in response to the intracellular $\mathrm{pH}$ and $\mathrm{GSH}$ concentration. The stimulus-dependent release of the SLs from the GSH/pH-NS was confirmed by in vitro experiments with prostate cancer cell lines.

Pollock et al. demonstrated that MEB55 and ST362 had the greatest cytotoxic effects in prostate and colon cancer cells compared to other SLs [11]. However, the SLs were evaluated in acetone in this study due to their low aqueous solubility, underscoring the need for more soluble carriers for preclinical and clinical applications. We observed a similar $\mathrm{IC}_{50}$ value for ST362 dissolved in N-methylpyrrolidone to the value reported by Pollock et al. The $\mathrm{IC}_{50}$ values of free MEB55 (6.4 and $6.5 \mu \mathrm{M}$ for DU145 and PC-3
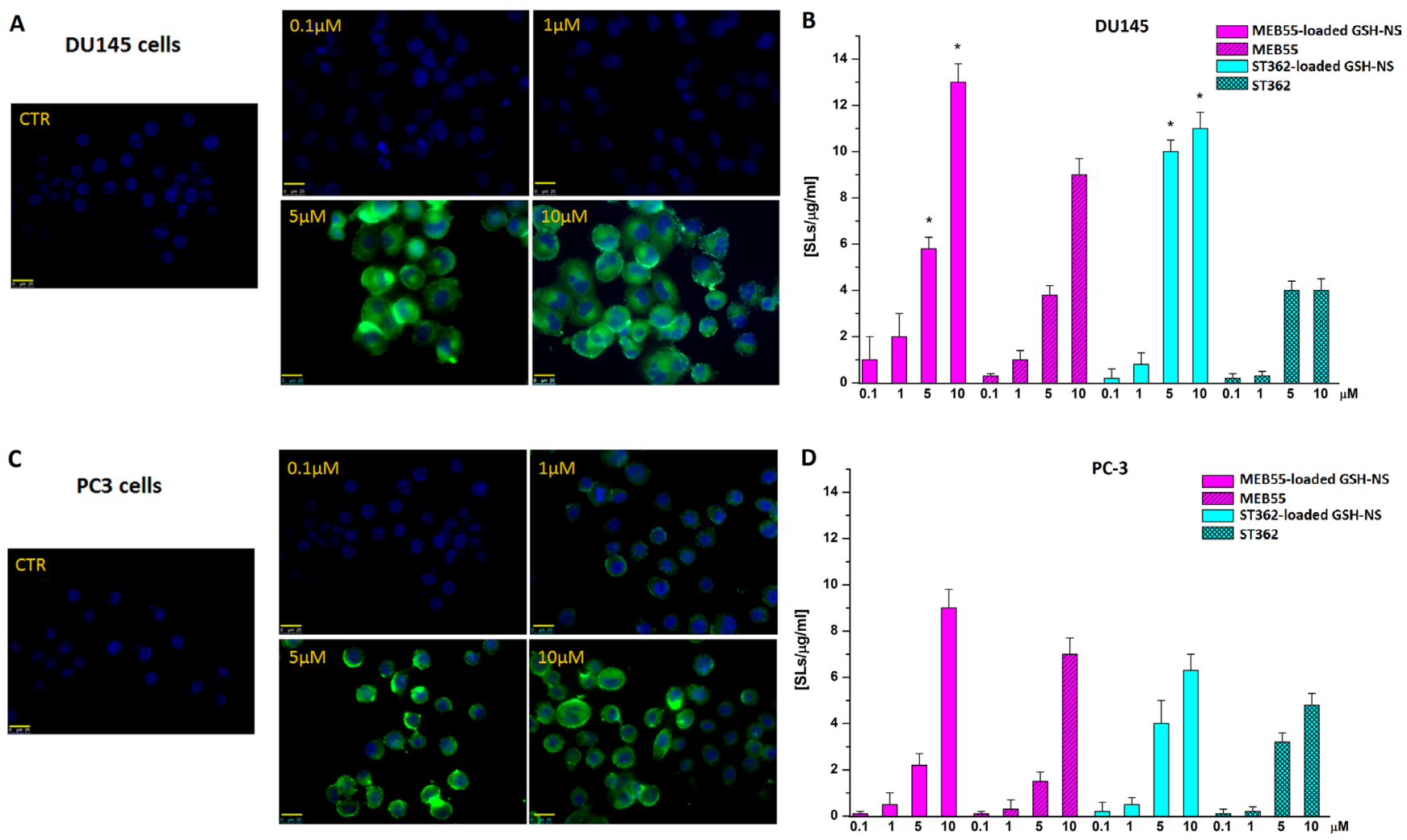

Figure 11: Fluorescence images (400X magnification) of the GSH/pH-NS (green) in DU-145 (A) and PC-3 (C) cells. Comparison between untreated cells (CTR) and cells treated with 0.1-10 $\mu \mathrm{M} \mathrm{GSH} / \mathrm{pH}-\mathrm{NS}$ after $4 \mathrm{~h}$; (B) Intracellular SL content in DU-145 (B) and PC-3 (D) cells $24 \mathrm{~h}$ after treatment with $0.1-10 \mu \mathrm{M}$ free SLs or SL-loaded GSH/pH-NS. 
cells, respectively) were lower when it was dissolved in N-methylpyrrolidone, than those reported by Pollock et al. (33.5 and $27.3 \mu \mathrm{M}$ for DU145 and PC-3 cells, respectively).

In this work, we investigated whether the SLloaded GSH/pH-NS reduced the viability of prostate cancer cells in vitro. The MEB55-loaded GSH/pH-NS demonstrated greater inhibition of DU145 cell (high GSH content) viability in MTT assays compared to free MEB55. In contrast, they had a lower effect on the viability of PC-3 cells (low GSH content). LDH assays revealed that treatment with the $\mathrm{GSH} / \mathrm{pH}-\mathrm{NS}$ resulted in cell death, which was dependent on the intracellular GSH content. Treatment with free SLs also induced cell death in PC-3 cells, which was likely related to oxidative stress. Limited LDH release was observed in the other cell types $24 \mathrm{~h}$ after treatment. Annexin-V staining indicated that the DU145 cells underwent apoptotic cell death, as previously showed by Pollock et al. [11-12]. We also performed colony formation assays, which confirmed the dependence of the cellular responses on the intracellular GSH content.

Daga et al. [35] demonstrated that DU145, PC-3, HCT116, and HT29 cells had GSH contents of 12, 7, 14, and $4 \mu \mathrm{g}$ per mg of protein, respectively. Additionally, they showed that the level of reactive oxygen species (ROS) was inversely correlated with the GSH content. PC-3 and HT29 cells displayed higher levels ROS than DU145 and HC116 cells, suggesting they had reduced antioxidant potential [35]. These data are consistent with the in vitro behavior of the SL-loaded GSH/pH-NS that we observed.

In summary, this work was focused on the design and development of a stimuli responsive nanomedicine for the delivery of SLs in prostate cancer cells. It is the proof of concept of the feasibility to incorporate SLs in a nanocarrier to improve effectiveness. We demonstrated that the incorporation of two SLs into GSH/pH-NS enhanced their cytotoxic effects on prostate cancer cells. Our data indicate that $\mathrm{GSH} / \mathrm{pH}-\mathrm{NS}$ are dual stimuli responsive nanocarrier that may favor the selectively controlled release of SLs in target cancer cells.

\section{MATERIALS AND METHODS}

The $\beta$-CD was a gift from Roquette Italia (Cassano Spinola, Italy). All reagents were analytical grade and obtained from Sigma-Aldrich (St. Louis, MO, USA) unless otherwise specified. Cell culture reagents were purchased from Gibco/Invitrogen (Life Technologies, Paisley, UK) unless otherwise specified. The SL analogues were synthesized as previously described [14]. ST362 was a gift from StrigoLab Srl (Turin, Italy).

\section{Cell lines and culture}

Cell lines were obtained from ATCC (Manassas, VA, USA). The cells were cultured as a monolayer in RPMI 1640 medium supplemented with $10 \% \mathrm{FCS}, 100 \mathrm{U} \cdot \mathrm{mL}^{-1}$ penicillin, and $100 \mu \mathrm{g} \cdot \mathrm{mL}^{-1}$ streptomycin at $37^{\circ} \mathrm{C}$ in a $5 \%$ $\mathrm{CO}_{2}$ humidified atmosphere.

\section{Synthesis of the GSH/pH-NS}

$\mathrm{GSH} / \mathrm{pH}-\mathrm{NS}$ were generated using the method developed by Trotta et al. [28]. Briefly, $\beta$-CD was reacted with pyromellitic dianhydride (crosslinking agent) and 2-hydroxyethyl disulfide (DHES) in dimethylsulfoxide (DMSO) in order to insert disulfide bridges in the polymer matrix. A total of $4.0 \mathrm{~g}(3.52 \mathrm{mmol})$ of anhydrous $\beta-\mathrm{CD}$ (desiccated in an oven at $100^{\circ} \mathrm{C}$, up to constant weight) was dissolved in $16 \mathrm{~mL}$ of DMSO in a $100 \mathrm{~mL}$ round bottom flask. Once a clear solution was obtained, $0.400 \mathrm{~g}$ (2.59 $\mathrm{mmol})$ of DHES and $4.0 \mathrm{~mL}(28.70 \mathrm{mmol})$ of triethylamine were added and the solution stirred for approximately $30 \mathrm{~min}$. Finally, $11.01 \mathrm{~g}$ (48.96 mmol) of pyromellitic dianhydride was added to the reaction. The gelation point was reached after several minutes but the reaction was incubated for 24 $\mathrm{h}$ to reach completion. Once the reaction was complete, the monolith block was crushed with a mortar to obtain a coarse powder. The powder was rinsed with an excess of deionized water, filtered under vacuum, and then purified by means of Soxhlet extraction with acetone (for approximately $24 \mathrm{~h}$ ). After air-drying, a white powder was collected and stored in a desiccator at room temperature.

\section{Elemental analysis}

CHNS elemental analysis was performed to quantify the sulfur content in the GSH/pH-NS and compare it with the theoretical value. The CHNS analyses were performed in triplicate in a Thermo Electron Corporation Flash EA 1112 series CHNS-O Analyzer, using 2,5-bis (5-tertbutyl-benzoxazol-2-yl) thiophene (BBOT) as an external standard. Approximately $2.5 \mathrm{mg}$ of each sample was placed in a tin capsule. An approximately equal quantity of $\mathrm{V}_{2} \mathrm{O}_{5}$ was then added as a catalyst.

\section{SSNMR spectroscopy}

SSNMR spectra were acquired using a Jeol ECZR 600 instrument, operating at 600.17 and $150.91 \mathrm{MHz}$ for ${ }^{1} \mathrm{H}$ and ${ }^{13} \mathrm{C}$ nuclei, respectively. Samples were packed into cylindrical zirconia rotors with a $3.2 \mathrm{~mm}$ optical density (OD) and a $60 \mu \mathrm{L}$ volume. The ${ }^{13} \mathrm{C} \mathrm{CP} / \mathrm{MAS}$ spectra were acquired at a spinning rate of $20 \mathrm{kHz}$ using a ramp cross-polarization pulse sequence with a contact time of $3.5 \mathrm{~ms}$, a $90^{\circ}{ }^{1} \mathrm{H}$ pulse of $2.189 \mu \mathrm{s}$, (optimized) recycle delays of $2.26 \mathrm{~s}$, and a total of 2,833 scans. A two-pulse phase modulation decoupling scheme was used to collect all spectra, with a radiofrequency field of $108.5 \mathrm{kHz}$. The chemical shift scale was calibrated relative to the methylene signal of glycine (43.7 ppm).

\section{Preparation of blank GSH/pH-NS}

A top-down method was used to generate the GSH/ $\mathrm{pH}-\mathrm{NS}$ from a coarse powder. First, a weighted amount of 
the GSH/pH-NS was suspended in saline solution $(0.9 \%$ w/v NaCl) at a concentration of $10 \mathrm{mg} / \mathrm{mL}$ while stirring at room temperature. The suspension was then dispersed using a high shear homogenizer (Ultraturrax ${ }^{\circledR}$, IKA, Konigswinter, Germany) for 5 minutes at 24,000 rpm. The samples were subjected to HPH for 90 minutes at a back pressure of 500 bar using an EmulsiFlex C5 instrument (Avestin, Mannheim, Germany) to further reduce the sizes of the NS and obtain a homogenous distribution. The GSH/pH-NS were then purified by dialysis (Spectrapore cellulose membrane, MWCO: 12,000 Da) and stored at $4^{\circ} \mathrm{C}$. A fraction of the $\mathrm{GSH} / \mathrm{pH}-\mathrm{NS}$ was freeze-dried using a Modulyo Freeze-Dryer (Edwards, Crawley, UK).

\section{Preparation of SL-loaded GSH/pH-NS}

SL-loaded GSH/pH-NS were obtained by adding $1.5 \mathrm{mg} / \mathrm{mL}$ MEB55 or ST362 dissolved in $100 \mu \mathrm{L}$ of $\mathrm{N}$-methylpyrrolidone to an aqueous suspension of GSH/pH$\mathrm{NS}$ at a concentration of $10 \mathrm{mg} / \mathrm{mL}$. The mixture was then stirred at room temperature in the dark for $48 \mathrm{~h}$. Unloaded SLs were separated from SL-loaded GSH/pH-NS by mild centrifugation. The SL-loaded GSH/pH-NS were then stored at $4^{\circ} \mathrm{C}$ until use. A select volume was freeze-dried to generate a solid powder. Weighted quantities of the SLs were dissolved in N-methylpyrrolidone and then diluted in $0.9 \% \mathrm{w} / \mathrm{v} \mathrm{NaCl}$ for use as controls.

\section{Preparation of fluorescently labelled GSH/pH-NS}

Fluorescently labelled GSH/pH-NS were obtained by adding $0.1 \mathrm{mg} / \mathrm{mL}$ 6-coumarin to an aqueous suspension of blank GSH/pH-NS at a concentration of $10 \mathrm{mg} / \mathrm{mL}$ as described above and then stirring the solution for $24 \mathrm{~h}$ at room temperature in the dark. Unloaded 6-coumarin was separated from fluorescent GSH/pH-NS by mild centrifugation.

\section{In vitro characterization of the GSH/pH-NS}

The average diameter and polydispersity index of the GSH/pH-NS were determined using photon correlation spectroscopy (PCS). The zeta potential was determined from the electrophoretic mobility using a NanoBrook 90Plus instrument (Brookhaven Instruments Corporation, Brookhaven, NY, USA). Samples of each diluted solution of NS were placed in the electrophoretic cell and an electric field of approximately $15 \mathrm{~V} / \mathrm{cm}$ applied. PCS was performed on GSH/pH-NS diluted in filtered distilled water with a scattering angle of $90^{\circ}$ and at $25^{\circ} \mathrm{C}$. The morphologies of the GSH/pH-NS were analyzed by TEM using a Philips CM10 instrument (Eindhoven, Netherlands). Aqueous suspensions of the GSH/pH-NS were sprayed onto Formvar-coated copper grids and air-dried prior to imaging.

\section{Thermal analysis}

DSC was performed with a PerkinElmer DSC/7 (PerkinELmer, Shelton, CT, USA) equipped with a TAC
7/DX instrument controller. The instrument was calibrated using indium. The heating rate was $10^{\circ} \mathrm{C} / \mathrm{min}$ and the temperature range was $25-250^{\circ} \mathrm{C}$. Standard aluminum sample pans (Perkin-Elmer) were used to prepare samples. An empty pan was used as a reference standard. The analyses were performed in triplicate on $3 \mathrm{mg}$ freeze-dried samples under a nitrogen purge.

\section{FTIR analysis}

FTIR spectra of free SLs, blank GSH/pH-NS, and SL-loaded GSH/pH-NS were obtained in the 4000-650 $\mathrm{cm}^{-1}$ region using a Spectrum 100 FT-IR instrument (PerkinElmer). Data were analyzed using the Spectrum Software version 10.03.05 (PerkinElmer).

\section{Quantitative analysis of SL by HPLC}

The concentrations of MEB55 and ST362 were quantified using an HPLC system consisting of a PerkinElmer PUMP 250B, equipped with a Flexar UV/Vis LC spectrophotometer detector (PerkinElmer, Waltham, MA, USA). We utilized a reversed phase Agilent TC C18 column $(150 \mathrm{~mm} \times 4.6 \mathrm{~mm}$, pore size $5 \mu \mathrm{m}$; Agilent Technologies, Santa Clara, CA, USA). The mobile phase consisted of a mixture of acetonitrile and water $(85: 15 \mathrm{v} / \mathrm{v})$, which was degassed and pumped through the column at a flow rate of $1 \mathrm{~mL} / \mathrm{min}$. The ultraviolet detector was set at $294 \mathrm{~nm}$ and $300 \mathrm{~nm}$ for MEB55 and ST362, respectively. The SL concentrations were calculated using a calibration curve and an external standard. A total of $1 \mathrm{mg}$ of MBE55 or ST362 was placed in a volumetric flask and dissolved in acetonitrile to obtain a standard stock solution. This solution was then diluted in the mobile phase to generate the series of standard solutions. Linear calibration curves were obtained over a concentration range of $0.5-25 \mu \mathrm{g} / \mathrm{mL}$. Both compounds had regression coefficients of 0.999 .

\section{Analysis of the loading capacity of the GSH/pH-NS}

Weighted quantities of freeze-dried MEB55- or ST362-loaded GSH/pH-NS were dispersed in $5 \mathrm{~mL}$ of acetonitrile. After sonication and centrifugation, the supernatants were analyzed by HPLC and the levels of MEB55 and ST362 in the GSH/pH-NS quantified. The loading capacity of the SL-loaded GSH/pH-NS was calculated using the following equation: [amount of SL/ weight of NS] $\times 100$.

\section{Analysis of the in vitro release kinetics of the SL- loaded GSH/pH-NS}

In vitro assays of SL release from the GSH/pH-NS were performed using a multi-compartment rotating cell consisting of donor and receiving chambers separated by a cellulose membrane (Spectrapore, MWCO: 12,000 Da). A $1 \mathrm{~mL}$ volume of the SL-loaded GSH/pH-NS was placed 
in the donor chamber while $1 \mathrm{~mL}$ of phosphate-buffered saline (PBS) $\mathrm{pH} 7.4$ containing $0.1 \%$ sodium dodecyl sulfate (SDS) to ensure drug solubility was placed in the receiving chamber. In vitro release studies were performed in the presence of increasing concentrations of GSH (1-20 $\mathrm{mM}$ ) in the receiving compartment. The receiving phase was withdrawn at regular intervals and replaced with an equal volume of fresh solution in order to maintain sink conditions. The concentrations of the SLs were then analyzed by HPLC. The effects of $\mathrm{pH}$ on SL release from the GSH/pH-NS were analyzed using phosphate buffer containing $1 \mathrm{mM}$ GSH at either $\mathrm{pH} 5.5$ or 7.4 as the receiving phase.

\section{In vitro studies of the stability of the SL-loaded GSH/pH-NS}

The physical stability of blank and SL-loaded GSH/ pH-NS was analyzed in RPMI 1640 cell culture medium supplemented with $10 \% \mathrm{FCS}$ or in $0.9 \% \mathrm{NaCl}$ as a control. The SL-loaded GSH/pH-NS were incubated at $37^{\circ} \mathrm{C}$ and then the average diameter and Z-potential analyzed at 0 , 8 , and $24 \mathrm{~h}$.

\section{In vitro evaluation of SL chemical stability over time}

The chemical stability of MEB55 and ST362 was evaluated in acetone, $\mathrm{N}$-methylpirrolidone- $0.9 \% \mathrm{NaCl}$, and in the GSH/pH-NS by examining the SL concentration over time using HLPC as described above. The samples were stored at $4^{\circ} \mathrm{C}$ and analyzed at fixed time $(0,1,7,14$, $28,60,90$ days).

\section{Analysis of the intracellular concentrations of ST362 and MEB55}

Prostate cancer cells $\left(3 \times 10^{3} /\right.$ well $)$ were seeded in 96 -well plates and incubated at $37^{\circ} \mathrm{C}$ in a $5 \% \mathrm{CO}_{2}$ humidified atmosphere for $24 \mathrm{~h}$. The cells were then incubated with increasing concentrations $(0.1-10 \mu \mathrm{M})$ of MEB55, ST362, MEB55-loaded GSH/pH-NS, or ST362loaded GSH/pH-NS for $24 \mathrm{~h}$. Following the incubation, the cells were washed and lysed with a saturated solution of ammonium sulfate, and $100 \mu \mathrm{L}$ of an acetonitrile: water mixture $(70: 30 \mathrm{v} / \mathrm{v})$ added to the solution. The samples were then centrifuged at $4^{\circ} \mathrm{C}$ for $10 \mathrm{~min}$ and the supernatants collected and diluted with the mobile phase. The samples were then vortexed for $2 \mathrm{~min}$, centrifuged, and the concentrations of the SLs in the supernatants quantified by HPLC as described above. The cellular uptake of ST362 and MEB55 was expressed as the intracellular SL concentration in $\mu \mathrm{g} / \mathrm{mL}$.

\section{Cell viability assays}

MTT assays were performed to assess the viability of DU-145 and PC-3 prostate cancer cells. Cells $\left(2 \times 10^{3} /\right.$ well) were seeded into 96-well plates and incubated at $37^{\circ} \mathrm{C}$ in a $5 \% \mathrm{CO}_{2}$ humidified environment for $24 \mathrm{~h}$. The cells were then treated with increasing concentrations $(0.1-10 \mu \mathrm{M})$ of MEB55, ST362, or the SL-loaded GSH/ $\mathrm{pH}-\mathrm{NS}$. After $24 \mathrm{~h}$, the absorbance was measured at $570 \mathrm{~nm}$ and the percentage of viable cells calculated using the manufacturer's protocol. Untreated control cells were normalized to $100 \%$. Eight replicates were performed for each data point and a total of five independent experiments were performed.

\section{LDH assays of cytotoxicity}

$\mathrm{LDH}$ leakage was estimated by measuring $\mathrm{LDH}$ activity in cell culture supernatants and cell lysates using a CytoTox 96 Non-Radioactive Cytotoxicity Assay Kit (Promega, Madison, WI, USA) according to the manufacturer's protocol [52]. DU-145, PC-3, HCT116, or HT29 cells $\left(2 \times 10^{3} /\right.$ well $)$ were seeded into 96-well plates and incubated with increasing concentrations (0.1-5 $\mu \mathrm{M})$ of MEB55, ST362, or the SL-loaded GSH/pH-NS for $24 \mathrm{~h}$. Following the incubation, $50 \mu \mathrm{L}$ of the Cytotox 96 Reagent was added to cell supernatants and the cells incubated at room temperature in the dark for $20 \mathrm{~min}$. Culture medium was used as a control (background). Untreated control cell lysates were used as the Maximum LDH Release Control. The reaction was then terminated by the addition of $50 \mu \mathrm{L}$ of the Stop Solution to each well. The absorbance was measured at $490 \mathrm{~nm}$ using a Victor Multilabel Plate Reader (PerkinElmer). LDH leakage was calculated using the following equation:

Percent cytotoxicity $=100 \times[$ Experimental LDH Release - absorption of untreated control (OD490)]/ [Maximum LDH Release - absorption of the untreated control (OD490)]. Four replicates were performed for each data point and a total of five independent experiments were performed.

\section{Colony formation assays}

Cells $\left(2 \times 10^{3} /\right.$ well $)$ were seeded into six-well plates. The following day, they were treated with increasing concentrations $(0.1-5 \mu \mathrm{M})$ of MEB55, ST362, or the two SL-loaded GSH/pH-NS. The media was exchanged after $24 \mathrm{~h}$ and the cells cultured for additional 7 days in drug-free media. Following the incubation, the cells were fixed and stained with $80 \%$ crystal violet (Sigma-Aldrich) and $20 \%$ methanol. Colonies were then photographed and counted using a BioRad Gel Doc system (Bio-Rad Laboratories, Milan, Italy). The cells were then washed and $30 \% \mathrm{v} / \mathrm{v}$ acetic acid added to induce dissolution of the crystal violet. The absorbance was measured at 595 
nm using a 96-well ELISA plate reader. A total of five independent experiments were performed.

\section{Annexin V staining}

Cells $\left(1.5 \times 10^{7}\right)$ were treated with increasing concentrations $(0.1-10 \mu \mathrm{M})$ of SLs or SL-loaded GSH/ pH-NS. After $24 \mathrm{~h}$, the cells were stained with Annexin $\mathrm{V}$ using the Annexin-V-FLUOS Staining Kit (Becton Dickinson, Franklin Lakes, NJ, USA) and analyzed by flow cytometry. Dead cells displayed shrunken/hypergranular morphologies and were Annexin-V-negative.

\section{In vitro studies of cellular uptake}

Flow cytometry assays of the uptake of fluorescently labelled GSH/pH-NS by DU-145 and PC-3 cells were performed using a FacsCalibur flow cytometer (BD Biosciences, San Jose, CA, USA). Cells were seeded in 6 -well plates $\left(10^{5} \mathrm{cell} /\right.$ well $)$ and incubated in the presence or absence of increasing concentrations $(0.1-10 \mu \mathrm{M})$ of fluorescently labelled GSH/pH-NS at either $37^{\circ} \mathrm{C}$ or $4^{\circ} \mathrm{C}$ for $4 \mathrm{~h}$. The cells were then washed twice with cold PBS to remove the unbound NS, trypsinized, and re-suspended in $500 \mu \mathrm{L}$ of $1 \%$ paraformaldehyde. Live cells were analyzed by flow cytometry and the results expressed as the percentage of positive (fluorescent) cells. Uptake was confirmed by fluorescence microscopy. Cells were seeded in 24-well plates $\left(5 \times 10^{5}\right.$ cell/well $)$ on sterile coverslips and incubated in the presence and absence of increasing concentrations $(0.1-10 \mu \mathrm{M})$ of the $\mathrm{GSH} / \mathrm{pH}-\mathrm{NS}$ at $37^{\circ} \mathrm{C}$ for $4 \mathrm{~h}$. The cells were then rinsed three times with cold PBS and fixed with 4\% paraformaldehyde for $30 \mathrm{~min}$ at $4{ }^{\circ} \mathrm{C}$. The nuclei were stained with DAPI $(1 \mathrm{mg} / \mathrm{mL}$; Sigma-Aldrich). The coverslips were then inverted and and mounted on glass slides. Images were acquired with a fluorescence microscope at 400X magnification (Leica DM5500 Microsystems, Milan, Italy) and analyzed using the LasX Software.

\section{Statistical analysis}

Data are expressed as the mean \pm standard error of the mean (SEM). Significant differences between experimental groups were detected by one-way ANOVA followed by Bonferroni correction using GraphPad InStat software (San Diego, CA, USA). A $p$ value $<0.05$ was considered statistically significant.

\section{Abbreviations}

13C CP/MAS: 13C Cross-Polarization/Magic Angle Spinning; $\beta$-CD: $\beta$-cyclodextrin; BBOT:2,5-bis(5-tertbutyl-benzoxazol-2-yl)thiophene; DAPI: 4',6'-diamidino2-phenylindole; DHES: 2-hydroxyethyl disulfide; DMSO: Dimethylsulfoxide; DSC: Differential scanning calorimetry; EPR: Enhanced permeability and retention; FTIR: Fourier transform infrared spectroscopy; GSH: Glutathione; GSH/pH-NS: Glutathione/pH-responsive nanosponges; HPH: High pressure homogenization: HPLC: High performance liquid chromatography; LDH: Lactate dehydrogenase; MTT: 2,3-bis[2-methoxy-4-nitro5sulphophenyl]-2H-tetrazolium-5carboxanilide; OD: Optical density; PBS: Phosphate-buffered saline; PCS: Proton correlation spectroscopy; ROS: Reactive oxygen species; SDS: Sodium dodecyl sulfate; SL: Strigolactone; SSNMR: Solid-state nuclear magnetic resonance; TEM: Transmission electron microscopy.

\section{Author contributions}

CL and MB synthesized all of the compounds; MA prepared the nanoformulations and performed the in vitro characterization; $\mathrm{BF}$ and $\mathrm{LG}$ performed cell culture experiments; FT and FC synthesized the GSH/pH-NS; CP and RC designed the experiments and analyzed the data; YK, HK, and RY conceived of the study and analyzed the data.

\section{ACKNOWLEDGMENTS}

We thank the COST Action FA1206 (Strigolactones: biological roles and applications) for providing networking opportunities.

\section{CONFLICTS OF INTEREST}

The authors declare that there are no conflicts of interest.

\section{FUNDING}

This work was supported by the University of Turin (ex $60 \%$ by Cavalli and Dianzani) Year 2015, Amici di Jean Foundation (Turin) CRT project and Compagnia di San Paolo (Stritool).

\section{REFERENCES}

1. Gomez-Roldan V, Fermas S, Brewer PB, Puech-Pages V, Dun EA, Pillot JP, Letisse F, Matusova R, Danoun S, Portais JC, Bouwmeester H, Bécard G, Beveridge CA, et al. Strigolactone inhibition of shoot branching. Nature. 2008; 455:189-194.

2. Lopez-Obando M, Ligerot Y, Bonhomme S, Boyer FD, Rameau C. Strigolactone biosynthesis and signaling in plant development. Development. 2015; 142:3615-3619.

3. Umehara M, Hanada A, Yoshida S, Akiyama K, Arite T, Takeda-Kamiya N, Magome H, Kamiya Y, Shirasu K, Yoneyama K, Kyozuka J, Yamaguchi S. Inhibition of shoot branching by new terpenoid plant hormones. Nature. 2008; 455:195-200. 
4. Kim HI, Xie X, Kim HS, Chun JC, Yoneyama K, Nomura T, Takeuchi Y, Yoneyama K. Structure-activity relationship of naturally occurring strigolactones in Orobanche minor seed germination stimulation. J Pestic Sci. 2010; 35:344-347.

5. Xie X, Yoneyama K, Yoneyama K. The strigolactone story. Annu Rev Phytopathol. 2010; 48:93-117.

6. Akiyama K, Matsuzaki K, Hayashi H. Plant sesquiterpenes induce hyphal branching in arbuscular mycorrhizal fungi. Nature. 2005; 435:824-827.

7. Bonfante P, Genre A. Arbuscular mycorrhizal dialogues: do you speak 'plantish'or 'fungish'?. Trends Plant Sci. 2015; 20:150-154.

8. Xie X, Yoneyama K, Kisugi T, Uchida K, Ito S, Akiyama K, Hayashi H, Yokota T, Nomura T, Yoneyama K. Confirming stereochemical structures of strigolactones produced by rice and tobacco. Mol Plant. 2013; 6:153-163.

9. Zwanenburg B, Nayak SK, Charnikhova TV, Bouwmeester HJ. New strigolactone mimics: structure-activity relationship and mode of action as germinating stimulants for parasitic weeds. Bioorg Med Chem Lett. 2013; $23: 5182$ 86. https://doi.org/10.1016/j.bmcl.2013.07.004.

10. Pollock CB, Koltai H, Kapulnik Y, Prandi C, Yarden RI. Strigolactones: a novel class of phytohormones that inhibit the growth and survival of breast cancer cells and breast cancer stem-like enriched mammosphere cells. Breast Cancer Res Treat. 2012; 134:1041-1055.

11. Pollock CB, McDonough S, Wang VS, Lee H, Ringer L, Li X, Prandi C, Lee RJ, Feldman AS, Koltai H, Kapulnik Y, Rodriguez OC, Schlegel R, et al. Strigolactone analogues induce apoptosis through activation of p38 and the stress response pathway in cancer cell lines and in conditionally reprogrammed primary prostate cancer cells. Oncotarget. 2014; 5:1683-98. https://doi.org/10.18632/oncotarget.1849.

12. Mayzlish-Gati E, Laufer D, Grivas CF, Shaknof J, Sananes A, Bier A, Ben-Harosh S, Belausov E, Johnson MD, Artuso E, Levi O, Genin O, Prandi C, et al. Strigolactone analogs act as new anti-cancer agents in inhibition of breast cancer in xenograft model. Cancer Biol Ther. 2015; 16:1682-1688.

13. Croglio MP, Hake JM, Ryan CP, Wang VS, Lapier J, Schlarbaum JP, Dayani Y, Artuso E, Prandi C, Koltai H, Agama K, Pommier Y, Chen Y, et al. Analogs of the novel phytohormone, strigolactone, trigger apoptosis and synergize with PARP inhibitors by inducing DNA damage and inhibiting DNA repair. Oncotarget. 2016; 7:13984-14001. https://doi.org/10.18632/oncotarget.7414.

14. Prandi C, Occhiato EG, Tabasso S, Bonfante P, Novero M, Scarpi D, Bova ME, Miletto I. New potent fluorescent analogues of strigolactones: synthesis and biological activity in parasitic weed germination and fungal branching. Eur $\mathrm{J}$ Org Chem. 2011; 20-21:3781-93. https://doi.org/10.1002/ ejoc. 201100616.

15. Maeda H. Tumor-selective delivery of macromolecular drugs via the EPR effect: background and future prospects. Bioconjug Chem. 2010; 21:797-802.
16. van Elk M, Murphy BP, Eufrásio-da-Silva T, O'Reilly DP, Vermonden T, Hennink WE, Duffy GP, Ruiz-Hernándeza E. Nanomedicines for advanced cancer treatments: Transitioning towards responsive systems. Int J Pharm. 2016; 515:132-164.

17. Ajorlou E, Khosroushahi AY. Trends on polymer- and lipidbased nanostructures for parenteral drug delivery to tumors. Cancer Chemother Pharmacol. 2017; 79:251-265.

18. Duchene D, Cavalli R, Gref R. Cyclodextrin-based Polymeric Nanoparticles as Efficient Carriers for Anticancer Drugs. Curr Pharm Biotechnol. 2016; 17:248-55.

19. Barrera G, Daga M, Ferrara B, Dianzani C, Pizzimenti S, Argenziano M, Cavalli R, Trotta F. Drug delivery nanoparticles in treating chemoresistant tumor cells. Curr Med Chem. 2017; 24:4800-15.

20. Cavalli R, Trotta F, Tumiatti W. Cyclodextrin-based nanosponges for drug delivery. J Incl Phenom. 2006; 56:209-213.

21. Trotta F, Zanetti M, Cavalli R. Cyclodextrin-based nanosponges as drug carriers. Beilstein J Org Chem. 2012; 8:2091-2099.

22. Trotta F, Dianzani C, Caldera F, Mognetti B, Cavalli R. The application of nanosponges to cancer drug delivery. Expert Opin Drug Deliv. 2014; 11:931-41.

23. Swaminathan S, Cavalli R, Trotta F. Cyclodextrinbased nanosponges: a versatile platform for cancer nanotherapeutics development. Wiley Interdiscip Rev Nanomed Nanobiotechnol. 2016; 8:579-601.

24. Minelli R, Cavalli R, Ellis L, Pettazzoni P, Trotta F, Ciamporcero E, Barrera G, Fantozzi R, Dianzani C, Pili R. Nanosponge-encapsulated camptothecin exerts anti-tumor activity in human prostate cancer cells. Eur J Pharm Sci. 2012; 47:686-694.

25. Gigliotti CL, Minelli R, Cavalli R, Occhipinti S, Barrera G, Pizzimenti S, Cappellano G, Boggio E, Conti L, Fantozzi R, Giovarelli M, Trotta F, Dianzani U, Dianzani C. In vitro and in vivo therapeutic evaluation of camptothecin-encapsulated $\beta$-cyclodextrin nanosponges in prostate cancer. J Biomed Nanotechnol. 2016; 12:114-127.

26. Gigliotti CL, Ferrara B, Occhipinti S, Boggio E, Barrera G, Pizzimenti S, Giovarelli M, Fantozzi R, Chiocchetti A, Argenziano M, Clemente N, Trotta F, Marchiò C, et al. Enhanced cytotoxic effect of camptothecin nanosponges in anaplastic thyroid cancer cells in vitro and in vivo on orthotopic xenograft tumors. Drug Deliv. 2017; 24:670-680.

27. Cheng W, Gu L, Ren W, Liu Y. Stimuli-responsive polymers for anti-cancer drug delivery. Mater Sci Eng C. 2014; 45:600-08.

28. Trotta F, Caldera F, Dianzani C, Argenziano M, Barrera G, Cavalli R. New glutathione bio-responsive cyclodextrin nanosponges. ChemPlusChem. 2016; 81:434. http://dx.doi. org/10.1002/cplu.201500531.

29. Phillips DJ, Gibson MI. Redox-sensitive materials for drug delivery: targeting the correct intracellular environment, 
tuning release rates, and appropriate predictive systems. Antioxid Redox Signal. 2014; 21:786-803.

30. Cheng R, Feng F, Meng F, Deng C, Feijen J, Zhong Z. Glutathione-responsive nano-vehicles as a promising platform for targeted intracellular drug and gene delivery. J Control Release. 2011; 152:2-12.

31. Chen X, Liu L, Jiang C. Charge-reversal nanoparticles: novel targeted drug delivery carriers. Acta Pharm Sin B. 2016; 6:261-267.

32. Jing T, Li T, Ruan Z, Yan L. pH-and glutathione-stepwiseresponsive polypeptide nanogel for smart and efficient drug delivery. J Mater Sci. 2018; 53:14933-43.

33. Schafer FQ, Buettner GR. Redox environment of the cell as viewed through the redox state of the glutathione disulfide/glutathione couple. Free Radic Biol Med. 2001; 30:1191-1212.

34. Traverso N, Ricciarelli R, Nitti M, Marengo B, Furfaro AL, Pronzato MA, Marinari UM, Domenicotti C. Role of glutathione in cancer progression and chemoresistance. Oxid Med Cell Longev. 2013; 2013:972913.

35. Daga M, Ullio C, Argenziano M, Dianzani C, Cavalli R, Trotta F, Ferretti C, Zara GP, Gigliotti CL, Ciamporcero ES, Pettazzoni P, Corti D, Pizzimenti S, Barrera G. GSHtargeted nanosponges increase doxorubicin-induced toxicity "in vitro" and "in vivo" in cancer cells with high antioxidant defenses. Free Radic Biol Med. 2016; 97:24-37.

36. Swaminathan S, Pastero L, Serpe L, Trotta F, Vavia P, Aquilano D, Trotta M, Zara G, Cavalli R. Cyclodextrinbased nanosponges encapsulating camptothecin: physicochemical characterization, stability and cytotoxicity. Eur J Pharm Biopharm. 2010; 74:193-201.

37. Ansari KA, Vavia PR, Trotta F, Cavalli R. Cyclodextrinbased nanosponges for delivery of resveratrol: in vitro characterisation, stability, cytotoxicity and permeation study. AAPS PharmSciTech. 2011; 12:279-86.

38. Torne SJ, Ansari KA, Vavia PR, Trotta F, Cavalli R. Enhanced oral paclitaxel bioavailability after administration of paclitaxel-loaded nanosponges. Drug Deliv. 2010; 17:419-25.

39. Caldera F, Argenziano M, Trotta F, Dianzani C, Gigliotti L, Tannous M, Pastero L, Aquilano D, Nishimoto T, Higashiyama T, Cavalli R. Cyclic nigerosyl-1, 6-nigerosebased nanosponges: An innovative $\mathrm{pH}$ and time-controlled nanocarrier for improving cancer treatment. Carbohydr Polym. 2018; 194:111-121.

40. Bertrand N, Wu J, Xu X, Kamaly N, Farokhzad OC. Cancer nanotechnology: the impact of passive and active targeting in the era of modern cancer biology. Adv Drug Deliv Rev. 2014; 66:2-25.
41. Marano F, Frairia R, Rinella L, Argenziano M, Bussolati B, Grange C, Mastrocola R, Castellano I, Berta L, Cavalli R, Catalano MG. Combining doxorubicin-nanobubbles and shockwaves for anaplastic thyroid cancer treatment: preclinical study in a xenograft mouse model. Endocr Relat Cancer. 2017; 24:275-286.

42. Torne S, Darandale S, Vavia P, Trotta F, Cavalli R. Cyclodextrin-based nanosponges: effective nanocarrier for tamoxifen delivery. Pharm Dev Technol. 2013; 18:619-25.

43. Murugan K, Choonara YE, Kumar P, Bijukumar D, du Toit LC, Pillay V. Parameters and characteristics governing cellular internalization and trans-barrier trafficking of nanostructures. Int J Nanomedicine. 2015; 10:2191-206.

44. Bastings MM, Anastassacos FM, Ponnuswamy N, Leifer FG, Cuneo G, Lin C, Ingber DE, Ryu JH, Shih WM. Modulation of cellular uptake of DNA origami through control over mass and shape. Nano Lett. 2018; 18:3557-64.

45. Zhao J, Stenzel M. Entry of nanoparticles into cells: the importance of nanoparticle properties. Polym Chem. 2018; 9:259-272.

46. Salatin S, Maleki Dizaj S, Yari Khosroushahi A. Effect of the surface modification, size, and shape on cellular uptake of nanoparticles. Cell Biol Int. 2015; 39:881-890.

47. Zhang J, Tang H, Liu Z, Chen B. Effects of major parameters of nanoparticles on their physical and chemical properties and recent application of nanodrug delivery system in targeted chemotherapy. Int J Nanomedicine. 2017; 12:8483-8493.

48. Liao J, Zheng H, Fei Z, Lu B, Zheng H, Li D, Xiong X, Yi Y. Tumor-targeting and $\mathrm{pH}$-responsive nanoparticles from hyaluronic acid for the enhanced delivery of doxorubicin. Int J Biol Macromol. 2018; 113:737-747.

49. Yu L, Yao L, Yang K. Redox-and pH-responsive hydrogels: formulation and controlled drug delivery. J Porous Mater. 2016; 23:1581-89.

50. Jhaveri A, Deshpande P, Torchilin V. Stimuli-sensitive nanopreparations for combination cancer therapy. J Control Release. 2014; 190:352-370.

51. Dai W, Wang X, Song G, Liu T, He B, Zhang H, Wang X, Zhang Q. Combination antitumor therapy with targeted dualnanomedicines. Adv Drug Deliv Rev. 2017; 115:23-45.

52. https://ita.promega.com/resources/protocols/technicalbulletins/0/cytotox-96-non-radioactive-cytotoxicity-assayprotocol/. 